ESTUDIOS 

REVISTA DE DERECHO UNED, NÚM. 27, 2021

\section{PRECEDENTES DE LA LEY DE AGUAS DE 2 DE AGOSTO DE 1985}

BACKGROUND TO THE WATER LAW OF AUGUST 2, 1985

Álvaro Aguirre Pascual.

Ingeniero Industrial Superior

Graduado en Ciencia Política y Administración

Doctorando en el Programa de Derecho y Ciencias Sociales de la UNED.

Línea: La intervención de la Administración Pública en la Sociedad.

Sumario: 1. Introducción. 2. Ley de aguas de 3 de agosto de 1866. 3. Ley de aguas de 13 de junio de 1879. 4. El código civil de 24 de julio de 1889 y su relación con la ley de aguas de 1879. 5. Intentos de modificación de la ley de aguas de 13 de junio de 1879. 6. Conclusiones.

Resumen: Desde el segundo tercio del siglo XIX, momento en que se produce un salto socioeconómico basado en la agricultura, el agua se revela como el principal factor de desarrollo comenzando a regularse jurídicamente su uso. Estas regulaciones, dispersas y carentes de sistemática, obedecen principalmente a pactos entre intereses opuestos.

En 1866 nace la primera Ley de Aguas que jerarquiza sus usos, agrupa y ordena numerosos preceptos dispersos, trata de respetar el derecho consuetudinario y, dentro del marco liberal de la época, distingue entre aguas públicas y privadas.

Las fuertes tensiones políticas del periodo de 1867 a 1876 generan en España cambios legislativos constitucionales de gran calado que tuvieron impacto en el sector del agua por lo que nace la Ley de Aguas 
de 1879 , que sustituye a la anterior, y que centra su normativa en las aguas terrestres, regulando los derechos y deberes que se derivan del dominio de las aguas, de su uso y de su aprovechamiento, aunque sigue manteniendo un régimen jurídico privatista para las aguas subterráneas y otro administrativista para las aguas superficiales públicas.

Palabras clave: El agua como factor de desarrollo económico. Aguas públicas y aguas privadas. Usos consuetudinarios convertidos en ley. Ley de Minas de 1968. Dominio, uso y aprovechamiento. Derecho de aprovechamiento de aguas públicas por prescripción. Principio del interés general. Pozo ordinario y Pozo artesiano, de socavón o de galería. Código Civil.

Abstract: From the second third of the 19th century, when a socioeconomic improvement based on agriculture took place, the water revealed itself as the main development factor and its use began to be legally regulated. These scattered and unsystematic regulations were mainly due to pacts between parties with opposing interests.

In 1866 the first Water Law was born, which hierarchized its uses, grouped and ordered numerous dispersed precepts, tried to respect the customary law and, within the liberal framework of its time, differentiated between public and private water supply.

The strong political tensions of the period between the years 1867-1876, generated in Spain very important constitutional legislative changes that had an impact on the water sector with the Water Law of 1879 being born. This law replaces the previous one, and focuses its normative on terrestrial waters, regulating the rights and obligations that derive from the water property, use and economic exploitation, although it continues to maintain a private legal regime for groundwater and an administrative system for public surface water.

Keywords: Water as a factor of economic development. Public Waters and Private Waters. Customary use as a common law. Mine Law of 1868. Property; use and economic exploitation. Economic exploitation right of public waters by prescription procedure. General interest principle. Ordinary water well and artesian well, dug well or gallery well. Civil Code.

Recepción original: 7-9-2020

Aceptación original: 12-12-2020 


\section{INTRODUCCIÓN.}

Se realiza a continuación un análisis de la legislación en materia de aguas del periodo que abarca desde el segundo tercio del siglo XIX hasta la publicación de la Ley 29/1985, de 2 de agosto, “de Aguas". La importancia que en España ha tenido el agua para regadío agrícola ha hecho que éste se haya estudiado desde sus orígenes, generándose dos ópticas sobre sus comienzos y formas. En esta discusión sobre el origen de los regadíos españoles, según Morales Gil" "hay ya acuerdo derivado de las evidencias de que tal iniciativa fue acometida por los romanos, si bien aún hay quien se inclina por defender unos antecedentes prerromanos basándose sólo en algunas noticias de escritores clásicos y en muy pocos restos de obras hidráulicas de paternidad discutida". Finalizando ya la Edad Moderna "las Instrucciones de Intendentes Corregidores de 1749 y 1788 habian destacado la suma utilidad y conveniencia de fertilizar los campos con el aprovechamiento de todas las aguas que pudieran aplicarse a su beneficio, sacando, para ello, acequias de los ríos sin perjudicar su curso, y tratando, igualmente de descubrir las subterráneas" . A finales del S.XVIII y principios del XIX, Jovellanos $^{3}$ ponía de relieve la importancia del agua para el desarrollo del campo español, lo que veía como necesario y de difícil solución. De aquí los Reales Decretos de 19 de mayo de $1816^{4}$ y 31 de agosto de $1819^{4}$ pretendiendo la construcción de canales de riego, objetivo que se encontraba con serias dificultades en el Tesoro Público. Persistiendo en esta idea de establecimiento de riegos y de su mejor utilización para el desarrollo de la agricultura, se publican las Reales Órdenes de 14 de marzo de $1846^{5}$, -sobre empresas en relación con la navegación de los ríos, acequias y balsas, exigiendo autorización Real para cualquier uso o aprovechamiento de éstos-; la de 21 de agosto de $1849^{5}$, -aclarando la anterior-, y la de 5 de abril de $1859^{5}$, -exigiendo autorización gubernamental para cualquier obra hidráulica-. Todas estas Reales Órdenes eran definidoras del domi-

1 Morales Gil, A. en "Hitos históricos de los regadíos españoles" de Gil Olcina, A y Morales Gil, A. Ed.: Ministerio de Agricultura, Alimentación y Medio Ambiente, p-15.

2 Pérez Pérez, E, "V. Disposiciones decimonónicas sobre aguas. Ley de 1879", p.184. https://www.mapa.gob.es/ministerio/pags/Biblioteca/fondo/pdf/9999_7.pdf

3 Gaspar Melchor de Jovellanos (1744-1811) fue un escritor, jurista y político español perteneciente al movimiento reformador del despotismo ilustrado, perteneciente al tránsito entre los siglos XVIII y XIX. Sus principales escritos versaron sobre política, economía y agricultura, destacando en este último ámbito el Informe sobre la Ley Agraria publicado en 1795.

4 Pérez Pérez, E. op.cit. pp. 184-185.

5 Ibid. p.p. 186-188 
nio público de las aguas corrientes y de la abolición de la adquisición de aprovechamientos de aguas por prescripción, debiéndose guiar los usos y aprovechamientos de las aguas por autorizaciones o concesiones de la Administración Pública, dejando como criterio general que sólo serían aguas privadas las subterráneas alumbradas en predios de dominio privado. Por otra parte, el Proyecto nonato de 1851 de Código Civil -conocido como Proyecto García Goyena- trató muy ampliamente, en sus Arts. 484 a 505, "de las servidumbres de aguas", el uso de éstas, la prescripción, como goce no interrumpido por treinta años desde la construcción de obras para el aprovechamiento de aguas, y la propiedad de éstas. El Proyecto no prosperó al pretender la aplicación de un Derecho Civil común para toda España derogando los Derechos Forales, pero sí tuvo influencia en la redacción de la Ley de Aguas de 1866.

El Real Decreto de 29 de abril de $1860^{6}$, sobre aprovechamientos de aguas, jerarquiza los usos del agua y sigue esta línea de control por parte de la Administración. En cualquier caso, proliferaron normativas a este respecto con distintas ópticas, debido al contexto político de la época, muy polarizado y de gran tensión, lo que generaba intensos cambios legislativos, por lo que como precedentes de la Ley 29/1985, de 2 de agosto "de Aguas", resulta clave el estudio de la primera Ley de Aguas, dada en 1866, cuyo inicio de redacción se remonta a 1859, y de su sucesora la Ley de Aguas de 1879 que antecede a la citada Ley de Aguas de 1985.

La legislación de aguas del siglo XIX tiene como objetivo principal el desarrollo del riego agrícola y así lo manifiesta Pérez Pérez, E. ${ }^{7}$ al exponer que "la relevancia de la legislación decimonónica de aguas es muy importante en el desarrollo de los regadíos en España ya que con ella se consiguió sentar las bases de una ordenación de los aprovechamientos colectivos de las aguas superficiales y de una gestión desconcentrada y participativa de los mismos, fundamentalmente a través de las comunidades de regantes. Las principales limitaciones

6 Vid: Calvo Pereyra, Mariano "De las aguas tratadas bajo el punto de vista legal y con aplicación a las construcciones y abastecimientos de las ciudades en sus diferentes usos". Pág.313. Madrid-1862; Universidad Complutense; Departamento de Derecho Administrativo.: "El principio en que estriba el Real Decreto de 1860 es vasto y fecundo en resultados y modifica profundamente la legislación antigua. Prescindiendo absolutamente de la propiedad privada de las aguas, las pone de repente en manos de la autoridad suprema y exige que deban obtener previamente la concesión Real todos los que quieran directa o indirectamente hacer con ellas, en ellas o junto a ellas, cualquier cosa que modifique en lo más mínimo su actual estado".

7 Pérez Pérez, E, loc.cit.: "V. Disposiciones decimonónicas sobre aguas. Ley de 1879", p.201. 
vinieron de falta de respuesta de la iniciativa privada y de las propias dificultades que presentaba la ingeniería hidráulica de las obras", producto, esto último, de las circunstancias naturales y geográficas de España, lo que fuerza a unas legislaciones complejas en esta materia de aguas, exponiendo, a este respecto, el Profesor Martín Retortillo ${ }^{8}$, que "la necesidad de una distribución adecuada de los caudales, la primacía del riego y la necesidad de compatibilizar los distintos aprovechamientos entre sí, hacen que se desarrolle, históricamente, una compleja normatividad en materia de aguas públicas en la que también se ha resuelto la propia conducta de la Administración Pública en esta materia". Con respecto a la situación del segundo tercio del pasado siglo XIX añade que "a la necesidad de respetar unas situaciones existentes, se une la insoslayable exigencia de una mayor explotación y toda esta problemática e inquietud que se genera va siendo recogida por el derecho positivo"10.

De aquí la profusión de normativas que van apareciendo, desde las postrimerías de los años 30 del siglo XIX, en función de los usos a los que se pretende destinar las aguas y de las necesidades de coordinación de intereses opuestos, lo que produce la formación de unas normativas, acumulativas y de aluvión, exentas de sistematización, dirigidas a parchear situaciones sectorizadas, lo que va generando un corpus muy complejo y desordenado, todo ello, fundamentalmente, fruto de un incipiente desarrollo socioeconómico que comienza a producirse en la segunda mitad del siglo XIX en un contexto político muy tensionado, en el que el agua es factor primordial de ese desarrollo.

La Real Orden de 11 de julio de $1856^{11}$, -muy a finales del bienio progresista- nombraba una Comisión ministerial encargada de examinar un estudio que se dirigía a la redacción de un Proyecto de Ley de Abastecimiento de Agua a Poblaciones, pero que a juicio de los Órganos Públicos decisores no se agotaba en esta materia de Abastecimiento de Agua a Poblaciones, sino que la trascendía abarcando una normativa general sobre las aguas. De aquí que, por Real Decreto de 27 de abril de 185912, -bajo gobierno de O’Donell con la

8 Martín-Retortillo Baquer, S.: "La elaboración de la Ley de Aguas de 1866" pp. 11-54. Revista de la Administración Pública, núm. 32. (mayo- agosto 1960); Ed. Instituto Estudios Políticos (Madrid). Reeditada por Centro de Estudios Políticos y Constitucionales, 2014. Madrid.

9 Ibid. Página 14.

10 Ibid. Página 14.

11 Valle Ribas, J. "Ley de aguas de 1866". https://gutierrezlabrador.com/la-ley-deaguas-de-1866/ ; 2019.

12 Pérez Pérez, E. op.cit. pp. 190. 
Unión Liberal- se creaba la Comisión que habría de elaborar el proyecto de la que fuera la primera Ley de Aguas, publicada en 1866.

El gran impulso que se pretendía dar al desarrollo de la economía agraria, vía expansión de los riegos, buscaba plantear un cambio en la política de aguas de España, lo que para el regeneracionista Joaquín Costa ${ }^{13}$, -impulsor de una decidida intervención estatal directa en la financiación y en la ejecución de obras hidráulicas al servicio del regadío-, constituía una misión social. Esta política hidráulica se realiza por medio de dos Leyes de Aguas, la de 1866 y la de 1879, que, a pesar de soportar las turbulencias del contexto político, contribuirían de manera decisiva al citado desarrollo socioeconómico.

\section{LEY DE AGUAS DE 3 DE AGOSTO DE 1866.}

Nace así la Ley de Aguas de 3 de agosto de 1866, sobre "Dominio y Aprovechamiento de Aguas". En su exposición de motivos que la acompañó para su sanción regia, la Comisión redactora manifiesta que "no necesita encarecer la importancia y dificultad del trabajo que se le ha encomendado, siendo su obra la primera de su género en Europa y si bien no original en gran parte de sus disposiciones, lo es ciertamente en su plan, estructura y método, que constituyen quizá lo más importante y difícil de esta clase de trabajos". Y se genera así esta Ley de Aguas de 1866 que lo hace "más que como una Ley Administrativa, como una Ley institucional, proporcionando un ordenamiento de las aguas arraigado en la conciencia social"14.

La Ley consta de trescientos artículos, -a lo largo de los cuales abarca los ámbitos de las aguas marinas, (éstas en los dos primeros Capítulos), y de las terrestres-, distribuidos en dieciséis capítulos agrupados en siete títulos, quedando reunidos los dos últimos Artículos, el doscientos noventa y nueve y el trescientos, bajo la rúbrica de Disposiciones Generales. El Artículo 299 dispone que "todo lo dispuesto en esta Ley es sin perjuicio de los derechos legítimamente adqui-

13 Joaquín Costa Martínez (1846-1911) político, jurista y economista español y el mayor representante del Regeneracionismo, movimiento intelectual que reflexiona, a finales del siglo XIX y principios del XX, sobre la nación española y sobre lo que interpretaban como su decadencia, proponiendo soluciones políticas que, en materia hidráulica, se basaban en la construcción de una red nacional de embalses y canales que tenían como objetivo el incremento de la superficie regada, lo que resolvería, además, el problema social.

14 Martín-Retortillo Baquer, S.: "La Ley de Aguas de 1866, antecedentes y elaboración". Centro de Estudios Hidrográficos; Volumen 31 de Publicaciones. Madrid, 1963 e id en "Sobre la reforma de la Ley de Aguas" Revista de la Administración Pública núm. 44 (mayo-agosto)-1964; CEPC-Madrid.p.27. 
ridos con anterioridad a su publicación, así como también del dominio privado que tienen los propietarios de aguas de acequias y de fuentes o manantiales, en virtud del cual las aprovechan, venden o permutan como propiedad particular". El Artículo 300 es derogatorio "quedando derogadas todas la Leyes, Reales Decretos, Reales Órdenes y demás disposiciones que acerca de las materias comprendidas en la presente Ley se hubiesen dictado con anterioridad a su promulgación y estuviesen en contradicción con ella". La Comisión redactora expone que "ha atendido los diversos intereses de cada localidad y la necesidad de conservar en las disposiciones de la ley tal amplitud y holgura, que dentro de ella quepan, y a sus preceptos puedan amoldarse, los variados usos y costumbres que se observan en el aprovechamiento de las aguas", por lo que mantiene haber logrado así respetar el derecho consuetudinario, si bien dentro del marco ideológico liberal de la época, por lo que distingue entre aguas públicas y aguas privadas, impregnándose de soluciones aportadas por el Derecho Romano de Aguas.

Pronto la Ley comienza a dividir las aguas en públicas y privadas bajo criterio de su origen y del terreno en donde se encuentren. Así, las aguas pluviales son propiedad del propietario del predio donde caen o se recogen ${ }^{15}$-no estableciéndose, por tanto, en esta Ley de 1866, inmediatez con respecto al agua directa de lluvia- mientras discurran por él, pero puede conservarlas acopiándolas en su predio, aunque de forma que no perjudique a terceros. Hay, pues, un derecho preferente de uso o aprovechamiento de las aguas -mientras circulan por el predio- y un derecho dominical en cuanto son recogidas y almacenadas por el dueño del predio en éste (Vid Alonso Moya, F. referencia 13). Sin embargo, las aguas de lluvia que discurren por ramblas o torrentes públicos son del dominio público de acuerdo con los Artículos 30 y 31. En cuanto a las aguas nacientes, también las divide en públicas y privadas en función del terreno donde se originan, continua o discontinuamente, según determina el Artículo 34, pero en este caso la Ley no entrega el dominio de las aguas así nacidas, en un predio de particular, del Estado, de las provincias o de los pueblos, al dueño respectivo de éstos, sino que les concede un derecho de uso y de aprovechamiento mientras discurran por el predio correspondiente, siendo públicas cuando salen de él si pasan a correr por cauces públicos formados naturalmente. En el apartado segundo de este precepto nace un principio de accesión ya que determina que "si las aguas, tras salir del predio de su nacimiento, y antes

15 Art. 30, Cap.III “Del dominio de las aguas pluviales” del Título II. Paralelamente, el Art. 31 hace públicas todas las aguas que discurren por torrentes o ramblas cuyos cauces sean del dominio público.

(C) UNED. Revista de Derecho UNED, núm. 27, 2021 
de llegar a los cauces públicos, entran a correr por otro predio de propiedad privada, su dueño las hace suyas para su aprovechamiento y luego el inmediatamente inferior y así sucesivamente", aunque siempre "el dueño del predio donde nacieran las aguas las aprovechará prioritariamente en la cantidad que viniera haciéndolo, siendo las mermas, si las hubiera, en desventaja de los siguientes" de acuerdo con el Artículo 40. En cuanto a las aguas muertas o estancadas, el Artículo 44 también las califica de públicas o de privadas en función del terreno donde se encuentren, siendo públicas si el terreno es público y privadas si el terreno es de dominio privado.

Las aguas subterráneas ${ }^{16}$ quedaron bajo el dominio privado del dueño del predio -Artículos 45 al 62- ya que, según el Artículo 45, "pertenecen al dueño de un predio en plena propiedad las aguas subterráneas que en él hubiere obtenido por medio de pozos ordinarios (cuya definición no establece pero debe entenderse que son pequeños en contraposición a los del Artículo 48) cualquiera que sea el aparato empleado para extraerlas", pudiendo todo propietario, Artículo 46, "abrir libremente pozos y establecer artificios para elevar aguas dentro de sus fincas, aunque con ello resulten amenguadas las aguas de sus vecinos" por lo que quedan reguladas, en el segundo inciso de este precepto, las distancias entre pozos tanto en la ciudad como en el campo. El Artículo 47 deja la "plena propiedad de las aguas subterráneas obtenidas en terrenos públicos a quien las hallare", si bien, previamente, debe de haber obtenido autorización del Ayuntamiento correspondiente para abrir pozos ordinarios. El Artículo 48 concede "la propiedad a perpetuidad de las aguas alumbradas por medio de pozos artesianos, socavones o galerías al alumbrador que las hiciese surgir a la superficie del terreno cualquiera que sea la dirección que el alumbrador quiera darles en todo momento".

La Ley, en su Artículo 207, fija la "preferencia concesional para los aprovechamientos de aguas públicas jerarquizando la prioridad en abastecimientos a poblaciones; abastecimientos a ferrocarriles; riegos; Canales de navegación; molinos y otras fábricas, barcas de paso, puentes flotantes; estanques para viveros o criaderos de peces". Regula también la Ley, en los Artículos 279 y siguientes, las Comunidades de Regantes y sus Sindicatos. La Ley, a pesar de la óptica con la que contempla las aguas privadas, estimula el aprovechamiento de éstas encaminándolas a satisfacer el interés general, pudiendo perder el dominio del todo, o de la parte no aprovechada, el dueño del predio en el que nacen unas aguas, que, tras haberlas utilizado, hubiera in-

16 Cap.VI "Del dominio de las aguas subterráneas", Artículos 45 a 62. 
terrumpido su aprovechamiento -(Artículos 39;41;42)- en los plazos que se establecen (un año y un día consecutivos, una vez transcurridos 20 años de la publicación de la Ley), adquiriendo el derecho quien, o quienes, por igual espacio de tiempo -un año y un día- las hubieren aprovechado.

El profesor Jordana de Pozas ${ }^{17}$ sintetizó el ideario de esta Ley, que encuentra impregnada de sentido jurídico, destacando la unificación de multitud de preceptos dispersos contenidos en distintos cuerpos legales y convirtiendo en rango de ley usos consuetudinarios, así como el predominio del punto de vista administrativo sobre el civil en la clasificación de las aguas en públicas y en privadas, estando toda la legislación orientada a favorecer el uso del agua para los fines de mayor interés público para lo que otorga a la Administración Pública una amplísima competencia en materia de aguas, si bien respondiendo al principio liberal en el amplio campo que deja para la actuación de los propios interesados como las Comunidades de Regantes y sus Sindicatos.

Como prueba de su interés por los derechos adquiridos, el Artículo 194 admite la posibilidad de la prescripción como título legítimo para llevar a cabo el aprovechamiento de aguas públicas, disponiendo que "el que durante veinte años hubiese disfrutado de un aprovechamiento de aguas públicas, sin oposición de la Autoridad o de terceros, continuará disfrutándolo aun cuando no pueda acreditar que obtuvo la correspondiente autorización", no considerando la Ley, en ningún caso, este procedimiento de la prescripción para acceder al dominio de agua pública.

Punto muy relevante de la Ley es el establecimiento de los plazos de duración de las concesiones para aprovechamiento de aguas públicas que exigen la correspondiente autorización del Gobierno (Artículo 234) siempre que hayan de tomarse más de cien litros por segundo, construyendo, para ello, presas, azudes u obras importantes y permanentes, tramitándose la concesión para caudales inferiores por el Gobernador de la Provincia; en su Artículo 236 la Ley, en cuanto a los citados plazos concesionales, dispone que "las concesiones de aguas hechas individual o colectivamente a los propietarios de las tierras para el riego de éstas serán a perpetuidad. Las que se hicieren a sociedades o empresas para regar tierras ajenas, mediante el cobro de un canon, serán por un plazo que no exceda de 99 años, transcurrido el cual, quedarán las tierras libres del pago del canon y pasará

17 Jordana de Pozas, L.: "La evolución del Derecho de las Aguas en España y en otros países" Revista de la Administración Pública número 37- pp.9-61.

(c) UNED. Revista de Derecho UNED, núm. 27, 2021 
a la comunidad de regantes el dominio colectivo de las presas, acequias y demás obras exclusivamente precisas para los riegos", con lo que queda establecido el principio de reversión de los activos construidos durante el periodo concesional. A este respecto, la Ley de Aguas de 1866 se inspiraba y recogía normativa contenida en la batería legislativa existente sobre aprovechamientos de aguas -Ley de 17 de julio de 1836 de expropiación forzosa ${ }^{18}$; Real Instrucción para promover y ejecutar las Obras Públicas aprobada por R.D. de 10 de octubre de 1845 ${ }^{18}$; Ley de 24 de junio de 1849 sobre servidumbre de acueducto $^{19}$; y Real Orden de 14 de marzo de $1846^{19}$, exigiendo autorización real previa para aplicación de aguas públicas a empresas, y su Real Orden aclaratoria de 21 de agosto de $1849^{19}$ - de forma que en las condiciones sobre las que se otorgaban las concesiones se hacía referencia a la duración del aprovechamiento otorgado disponiendo que "el concesionario disfrutará del canal y de todos sus aprovechamientos por el tiempo de 99 años, debiendo verificarse la entrega en perfecto estado de conservación", "interviniendo el Gobierno los productos de la concesión durante los últimos cuatro años como garantía de la entrega".

Pero la Ley de Aguas de 1866 entró en vigor en un momento político muy convulso con los cambios constitucionales de 1869 y de 1876 y los correspondientes enfrentamientos ideológicos y partidistas, por lo que no sólo no llegó a ver la luz el Reglamento de desarrollo de la Ley, sino que ésta sufrió modificaciones por el Decreto-Ley de 14 de noviembre de $1868^{20}$, por el que se aprobaban las "Bases Generales para la nueva legislación de obras públicas”, en las que

18 Mínguez Ben, E. “Antecedentes y elaboración de la primera Ley de Expropiación". https://dialnet.unirioja.es/descarga/articulo/893208.pdf

19 Pérez Pérez, E. op.cit. pp. 189 y 186.

20 Frax Rosales, Esperanza. Revista de Estudios Políticos (Nueva Época) ISNN 0048-7694; No 93 julio-septiembre 1996. Esperanza Frax Rosales; pp.513-528: "Las leyes de bases de obras públicas en el siglo XIX" Pág. 514: "El Decreto-Ley de 14 de noviembre de 1868 estableciendo bases generales para la nueva legislación de obras públicas trata de imprimir a éstas un nuevo carácter de acuerdo con el cambio ideológico experimentado con la revolución de septiembre. Poco después se presenta un proyecto de ley que tiende a tranquilizar a los futuros inversores garantizando todos sus derechos fuese cual fuese la situación política y declara la vigencia del Decreto de 14 de noviembre de 1868 hasta que la legislación de obras públicas hubiera sido modificada de acuerdo con las exigencias de la nueva situación política del país. Pero será la -posterior-nueva situación política del país, que corresponde a la Restauración, la que hará necesario revisar las bases de la legislación de obras públicas, de acuerdo con la diferente ideología imperante. La nueva Ley de bases para la legislación de obras públicas se aprueba el 19 de diciembre de 1876 y se completa rápidamente con la Ley General de Obras Públicas de 13 de abril de 1877 y el correspondiente Reglamento de 6 de julio de 1877. El marco legislativo básico queda vigente hasta entrado el siglo XX". 
ellas mismas señalan como objetivo "el radicalismo en toda su pureza", (aunque este radicalismo como tal era difícil de darse pues la libertad total de realización de obras públicas por cualquier persona por sí misma y sin intervención alguna del Estado era poco probable de producirse en la práctica) y por la Ley de 20 de febrero de 1870 , referente a la Construcción de" Canales y Pantanos de riego" y su correspondiente Reglamento, de 20 de diciembre de 1870 (Gaceta de Madrid 23 de diciembre de 1870), para su aplicación -Ley que otorgaba a los propietarios de Canales y de Pantanos la perpetuidad de las concesiones-, que alteran sustancialmente esta Ley de Aguas de 1866. Ambas normativas citadas responden a la misma motivación ideológica, partiendo de la consideración de que todas las concesiones "habrán de ser a perpetuidad" 21.

En efecto, en la Revolución de 1868, a la que antecede en 1866 la crisis financiera y de abastecimientos, se proclama una ideología de libertad económica por lo que el citado Decreto-Ley de 14 de noviembre de 1868 fija unas Bases Generales para una legislación de Obras Públicas en la que el Estado abandona su posición hegemónica de monopolista en cuanto a Obras Públicas se refiere, adoptándose, en este ámbito, un liberalismo económico tal que cualquier persona podía construir una infraestructura pública sin oposición ni intervención del Estado, otorgándose concesiones a perpetuidad. Consecuentemente, su Artículo 22, deroga los Artículos de la Ley de Aguas de 1866, en los casos en que ésta establecía concesiones por 99 años con reversión de los activos construidos, y se atribuyen ahora concesiones a perpetuidad. Deroga, además, otros preceptos que entrañaban restricciones a los particulares y atribuían facultades en beneficio de la Administración Pública. Este Decreto, empapado, pues, de individualismo, afirmaba en su preámbulo que "el monopolio del Estado en punto a obras públicas era un mal: ya no existe. El Estado constructor era contrario a los sanos principios económicos: ya no construye. El Estado, dedicando sus capitales a obras públicas es todavía un sistema vicioso y desaparecerá". Adicionalmente, la Ley de 20 de febrero de 1870, referente a la construcción de Canales y Pantanos de Riego, señala el ámbito de su aplicación en su Artículo $1^{\circ}$, que va dirigido a "las personas o Compañías que en adelante se propongan construir canales de riego, conforme a la presente Ley...", indicando su Artículo $8^{\circ}$ que "además de la perpetuidad

21 Martín-Retortillo Baquer, S.: "Dictamen sobre la perpetuidad de las concesiones de canales para riego otorgadas a empresa interpuesta con anterioridad a la Ley de Aguas de 1866". Revista de Administración Pública número 45; IEP-Madrid, 1964.; págs. 417-442. 
de las concesiones, de la libertad para establecer y modificar el canon o renta y de cuantos derechos otorga la legislación vigente a las empresas de canales de riego y pantanos....." estableciendo además el Artículo 16 la "posibilidad de que los beneficios otorgados por ella (la propia Ley) fueran aplicados a todas las empresas de canales y pantanos ya existentes y que no hubieran terminado las obras". Su Reglamento, de 20 de diciembre de 1870, en nada modifica, ni matiza, la perpetuidad de las concesiones, limitándose, obviamente, a establecer el procedimiento de las solicitudes para el otorgamiento de concesión.

Sin embargo, en su publicación en la Revista de Obras Públicas, "Consideraciones sobre el Decreto-Ley de 14 de noviembre de 1868"22, Núñez de Prado y Fernández aclara y matiza varios de los preceptos de este Decreto-Ley ante el hecho de que, a su juicio, éste "sólo contiene principios generales expuestos con vaguedad y falta de encadenamiento". Como liberal no radical matiza e interpreta la Norma bajo un análisis global de la misma, Norma que, expone, adopta "la remoción de estorbos al libre y desembarazado ejercicio de la actividad individual y colectiva". Núñez de Prado juzga inconveniente el radicalismo liberal que este Principio radicalista liberal inspira al Decreto-Ley ya en su Artículo $1^{\circ}$. Declara en su análisis que "la Norma parte de un dualismo que presenta, de una parte, (Artículo $1^{\circ}$ ) el interés particular al que se le otorga todo el radicalismo económico en su mayor pureza -consignando que cualquier persona puede acometer, sin intervención del estado, cualquier obra pública adquiriendo los elementos para ello, incluida la zona necesaria para establecer la obra$y$, de otra parte, el interés general (Artículo $2^{\circ}$ ) con la intervención de los agentes del Gobierno para dejar a salvo los sagrados derechos que la Administración no puede dejar que sean atropellados", consignándose explícitamente este extremo en el Artículo $3^{\circ}$, por lo que argumenta que "con la intervención administrativa el Gobierno tiene en su mano evitar la construcción de obras incompatibles entre sí, impidiendo toda competencia estéril y desastrosa para el servicio público, puesto que se reserva la facultad de otorgar la cesión de terrenos y la declaración de obra pública a la petición que más ventajas ofrezca". Añade que "el Gobierno tiene obligación y deber de examinar los proyectos bajo todos sus aspectos, en los órdenes físico, administrativo, político y social a fin de elegir el más útil y beneficioso, el cual sólo ha de realizarse con absoluta exclusión de los demás, mediante concesión al

${ }^{22}$ Nuñez de Prado y Fernández, Joaquín (Ingeniero de C.C.P. y político de la Unión Liberal): "Consideraciones sobre el Decreto Ley de 14 de noviembre de 1868". Revista de Obras Públicas; XXII; Tomo I (número 3) Año I (Tercera Serie); Madrid, $1^{\circ}$ de febrero de 1874; pp. 25-29; CPropiedad del Colegio de Ingenieros de Caminos, Canales y Puertos (España). 
efecto otorgada"23, manteniendo, además, que cualquier obra pública "haya o no competencia, antes de la autorización de su ejecución se ha de examinar su proyecto en relación con los derechos e intereses del Estado"24. En definitiva, en el análisis e interpretación que hace de este Decreto-Ley aunque defiende los Principios de éste, en su interpretación los modera y los coordina, por lo que ve que en el mismo se amparan la actividad individual (Art. $1^{\circ}$ ), la Gestión del Estado y su intervención, para salvar sus intereses, en cuanto haya afecciones del dominio público (Arts. $2^{\circ}$ y $3^{\circ}$ ), así como también el derecho de propiedad que quedaría conculcado si el Estado concediese a varios particulares la facultad de expropiar para un mismo fin.

Por tanto, la Ley de Aguas de 1866, quedó afectada por el citado Decreto-Ley de 14 de noviembre de 1868, de Bases generales para la nueva legislación de Obras Públicas y por la Ley de 20 de febrero de 1870, de Construcción de Canales y Pantanos de riego, fundamentalmente en lo concerniente a la duración del periodo concesional y en la reversión de los activos construidos durante el mismo y por el Reglamento de esta Ley.

Por otro lado, la Ley de 4 de marzo de 1868, de Minas, que reforma la de 6 de julio de 1859, y su Reglamento de 24 de junio de 1868, con las modificaciones introducidas por sus Bases Generales para la nueva legislación de Minas, aprobadas por Decreto-Ley de 29 de diciembre de $1868,{ }^{25}$ en el Artículo $1^{\circ}$ del epígrafe "Clasificación y dominio de las sustancias minerales", establece tres secciones para el "aprovechamiento de las sustancias útiles del reino mineral cualquiera que sea su origen y forma de yacimiento, hállense en el interior de la tierra o en su superficie", incluyendo en su Artículo $4^{\circ}$, las aguas subterráneas en la tercera sección. En su Artículo $5^{\circ}$ establece diferencias entre el "suelo, que comprende la superficie y termina hasta donde haya llegado el propietario en trabajos de cultivo o cimentaciones, distintos de la minería", y el "subsuelo que se extiende indefinidamente en profundidad desde donde el suelo termina y es dominio del Estado", quedando, por tanto, separadas ambas propiedades. Su artículo $9^{\circ}$ determina que "las sustancias de la tercera sección (en la que están incluidas las aguas subterráneas, según el citado Artículo $4^{\circ}$ ) sólo podrán explotarse en virtud de la concesión que otorgue el Gobierno con arreglo a las prescripciones de este Decreto-Ley". Dado que su Artículo 32 deroga toda legislación que se oponga a lo dispuesto en el De-

23 Id.

24 Id.

25 Por la redacción de El Consultor de los Ayuntamientos. Biblioteca de la Facultad de Derecho de Sevilla. http://fama2.us.es/fde/ocr/2006/legislacionDeMinas.pdf

(c) UNED. Revista de Derecho UNED, núm. 27, 2021 
creto-Ley, debían considerarse en oposición los Artículos 45; 46; 49 y 51 de la Ley de Aguas de 1866, en los que se dispone la plena propiedad de las aguas del dueño de un predio que en él las alumbrara y extrajera por cualquier medio, aplicándose, a partir de ese momento, a las aguas subterráneas los preceptos de la legislación minera. La Orden de 30 de marzo de 1872, que nace para aclarar esta colisión legislativa entre la Ley de Aguas de 1866 y la Ley de Minas de 1868 distingue entre alumbramiento y aprovechamiento en relación a la tramitación de expedientes ${ }^{26}$, el de alumbramiento por la Ley de Minas y el aprovechamiento por la Ley de Aguas de 1866 - o por la Ley de Canales y Pantanos de Riego de 20 de febrero de 1870- si las aguas alumbradas, una vez en superficie, tenían que circular por terrenos de dominio público o del dominio de un particular que no fuera el alumbrador, dando como procedente la citada derogación. Por tanto, el citado Decreto-Ley de 29 de diciembre de 1868 deroga, en este punto a la Ley de Aguas de 1866. No obstante, con posterioridad y periclitado ya el sexenio democrático, la Real Orden de 5 de diciembre de 1876, ya bajo el Régimen de la Restauración, establecía que el citado Decreto-Ley de 29 de noviembre de 1868 no podía afectar a la propiedad adquirida bajo la legislación anterior ni que tampoco el propósito del Legislador fuera entrar en contradicción con la Ley de Aguas, considerándose que este Decreto-Ley y la subsiguiente Orden aclaratoria de 30 de marzo de 1877 sólo se referían a las aguas subterráneas afloradas en terrenos Estatales. Esta Real Orden, por tanto, según esta consideración, declaraba que las disposiciones contenidas en la Legislación de Minas no derogaban ni modificaban los Artículos 45; 46; 49 y 51 de la Ley de Aguas de 1866, contenidos en el Capítulo VI "del dominio de las aguas subterráneas".

Puede observarse, pues, que los cambios políticos que se producen con el inicio de la Restauración llevan a cabo un intenso proceso de regulación legislativa de las Obras Públicas -cambio que ya podía anticiparse de la lectura del texto, antes expuesto, de Núñez de Prado, con la interpretación que hace del Decreto-Ley de 14 de noviembre de 1868- a partir de las Bases aprobadas por las Cortes en la Ley de 29 diciembre 1876, que dio lugar a diversos textos articulados

26 En su aclaración primera, textualmente dice: "Que en cuanto a la manera de tramitar los expedientes para el alumbramiento y aprovechamiento de las aguas subterráneas, es preciso distinguir dos periodos: primero, el del alumbramiento, que es pura y exclusivamente de la ley de minas; y el segundo el de aprovechamiento cuando ya en la superficie las aguas alumbradas tienen que ponerse en circulación por terrenos de dominio público o que no sean de la propiedad del que las alumbró, en cuyo período y circunstancias corresponde instruir los expedientes a la Dirección de Obras Públicas por la Ley de Aguas o por la de Canales de Riego". 
aprobados por el Gobierno. El primero de ellos fue la Ley General de Obras Públicas de 13 abril 1877, en la que se recuperaron y expandieron los principios de la Real Instrucción de 10 de octubre de 1845 , de forma que se volvieron a tomar las competencias de dirección facultativa y de vigilancia por el cuerpo de Ingenieros de Caminos (Artículos 16, 18 y 30), se sustituyó la perpetuidad de las concesiones de obras públicas por el plazo máximo de 99 años (Artículos 55 y 75), y se recondujo el principio de libertad -dispuesto por la citada legislación del Decreto-Ley de 14 de noviembre de 1868 y de la Ley de 20 de febrero de 1870 de Canales y Pantanos de Riego- a las obras de interés privado que no afectaran al dominio público ni requirieran expropiación (Artículo 52), recuperándose la posibilidad de obras subvencionadas con fondos públicos (Artículo 74). El ámbito de las Obras Públicas se agranda abarcando ahora, también, de acuerdo con el Artículo $1^{\circ}$, primer párrafo, a las "construcciones destinadas a servicios que se hallen a cargo del Estado, de las provincias y de los pueblos", así como también el ámbito correspondiente a las Obras Hidráulicas, que se amplía hasta "los trabajos relativos al régimen, aprovechamiento y policía de las aguas", de acuerdo con el segundo párrafo de este Artículo $1^{\circ}$.

Ante todas estas situaciones, la Ley de 3 de agosto de 1866, de Aguas, se acaba convirtiendo en un antecedente de la Ley de Aguas de 1879 , pese a la gran importancia que hay que imputarla en el desarrollo socioeconómico de España. En efecto, esta Ley de Aguas de 1866 reagrupó y sistematizó la legislación dispersa y sectorial hasta entonces existente, diferenciando entre aguas de dominio público y de dominio privado, contemplando su utilización productiva tanto para usos públicos como para usos particulares. Estableció la servidumbre de acueducto y se ocupó del correcto aprovechamiento de las aguas destinadas al riego -objetivo fundamental de la Ley- por parte de las Comunidades de Regantes. En definitiva, pese a sufrir las turbulencias políticas de esa época, "la Ley de Aguas de 1866 fue, en definitiva, un texto que honró hasta el extremo al derecho histórico español, así como sus principios y fuentes, sus instituciones clásicas, su contenido y alcance. Se convirtió en el primer código en materia de aguas, reunió o refundió la dispersión normativa y estableció todo un sistema"27.

27 Valle Rivas, J. "La ley de aguas de 1866"; 2019. Gutierrez Labrador, Abogados. https:/gutierrezlabrador.com/la-ley-de-aguas-de-1866/

() UNED. Revista de Derecho UNED, núm. 27, 2021 


\section{LEY DE AGUAS DE 13 DE JUNIO DE 1879.}

La Ley de Aguas de 13 de junio de 1879, nace bajo un régimen político liberal, estando sometida a la Constitución Española de junio de 1876, -fruto del sistema político de la Restauración-, y al amparo de la citada Ley General de Obras Públicas de 13 de abril de 1877. Consta de 256 artículos, más los dos Artículos, el 257 y el 258, que componen la rúbrica de las "Disposiciones Generales", cuyos preceptos respectivos, "de garantías de derechos adquiridos con anterioridad a su publicación" y "derogatorio" -derogando toda la legislación, Leyes, Decretos, Órdenes, que se hubiera dictado con anterioridad a su promulgación y se opusiera a la Ley- son los mismos que contemplaba la anterior Ley de Aguas de 1866.

La estructura de esta Ley de 1879 es análoga a la de la Ley de 1866, pero ahora desaparecen los primeros 29 Artículos -agrupados en los Capítulos Primero y Segundo del Título Primero- que la citada Ley de 1866 dedicaba, respectivamente, al "Dominio de las aguas del mar y de sus playas, de las accesorias y de las servidumbres de los terrenos contiguos" y al "uso y aprovechamiento de las aguas de mar $y$ de sus playas". Por tanto, el Título Primero de la Ley de Aguas de 1879, "Del dominio de las aguas Terrestres", regula en cuatro Capítulos, I; II; III y IV, respectivamente, "El dominio de las aguas pluviales"; "el dominio de las aguas vivas, manantiales y corrientes; "el dominio de las aguas muertas o estancadas" y "el dominio de las aguas subterráneas", que en el caso de la Ley de Aguas de 1866 correspondían al Título Segundo "De las aguas terrestres", Capítulos III, IV, V y VI, respectivamente. La parte de aguas maritimas segregada de la citada Ley de Aguas de 1866, que la Ley de Aguas de 1879 no recoge, se traslada a la Ley de Puertos de 7 de mayo de 1880, que la agrupa en sus dos primeros Capítulos, "del dominio de las aguas del mar litoral y de sus playas, de las accesiones y servidumbres de los terrenos contiguos" y "del uso y aprovechamientos del mar litoral y de sus playas", respectivamente, que totaliza en doce artículos. Esta segregación tuvo que obedecer a la comprensión de la diferencia entre aguas marinas y aguas terrestres, diferencia derivada de sus propias naturalezas y por los distintos usos a los que se destinaban.

La Ley de 1879 centra, pues, su regulación en las aguas terrestres -sean éstas de carácter superficial o subterráneas- fijando límites de éstas con sus correspondientes estudios sobre las mismas y manteniendo, en esencia, los mismos principios fundamentales y espíritu normativo que su antecesora de 1866, incluso con respecto a las concesiones a las que mantuvo bajo los mismos Principios básicos. 
Así, las concesiones para abastecimiento a poblaciones, para riego y para la industria, quedan recogidas, respectivamente, en los Artículos 170, 188 y 220 y los derechos y obligaciones de quienes hayan obtenido una concesión de aguas públicas para riegos, tanto las colectivas otorgadas a propietarios como las hechas a favor de Empresas o Sociedades y hubieran realizado obras para la realización de estos riegos, se recogen en la Sección IV "Del aprovechamiento de las aguas públicas para riego", del Capítulo XI "De los aprovechamientos especiales de las aguas públicas", del Título V, quedando las empresas obligadas a conservar "las obras en buen estado durante el tiempo de la concesión" 28 dejando establecidas "las condiciones de caducidad por la Ley General de Obras Públicas" 29 . Se regula en el Capítulo XIII, del Título V, "de la Comunidad de Regantes y sus sindicatos y de los jurados de riegos" en su Sección $1^{\text {a }}$ "de la comunidad de regantes y sus sindicatos", la formación y funcionamiento de colectivos para aprovechamientos de aguas para riegos, en función del número de regantes y de hectáreas a regar, de acuerdo con los Artículos 228 a 241.

La Ley, como cuestión relevante, contempla, en su Artículo 161, la utilidad pública como motivo de expropiación forzosa de todo aprovechamiento de aguas públicas, con la indemnización que correspondiera, en favor de otro que le preceda en interés público, pero no en favor de los que le siguieran. Y el Artículo 200 "declara de utilidad pública, a los efectos de la Ley de expropiación forzosa, las obras necesarias para el aprovechamiento de aguas públicas en riegos siempre que el volumen de éstas exceda de 200 litros por segundo". También esta Ley, como ya lo hacía el Decreto-Ley de 14 de noviembre de 1868 ya visto, se ocupa de garantizar seguridad a los capitales extranjeros que se juzgaban necesarios para el desarrollo socioeconómico a lograr, de forma que su Artículo 163 determinaba que "los capitales extranjeros que se empleen en la construcción de las obras y adquisición de terrenos para concesiones de canales de riego y navegación quedan bajo la salvaguardia del Estado, y están exentos de represalias, confiscaciones y embargos por causas de guerra".

Esta Ley de Aguas de 1879, establece tres criterios para la clasificación de las aguas: por su propiedad o dominio; por su origen; y por su especial naturaleza, debiendo en mi opinión añadir un cuarto criterio referente a su uso y/o aprovechamiento ${ }^{30}$, dada la importan-

28 Artículo 196, párrafo $1^{\circ}$.

29 Artículo 196, párrafo $2^{\circ}$.

30 En mi opinión, y de acuerdo con Alonso Moya, F. "Sobre las aguas de dominio público y de dominio privado", 1951, (Vid. siguiente referencia núm. 28), procede añadir este criterio. 
cia que la Ley concede al destino o uso a dar al agua. Por su propiedad quedan divididas en aguas de dominio público y en aguas de dominio privado. Por su origen quedan divididas en pluviales (Cap. $1^{\circ}$; Art. 1); vivas (manantiales); corrientes (ríos, arroyos, torrentes) (Cap. $2^{\circ}$; Art.4.2 y 3); muertas o estancadas (lagos, lagunas, charcas) (Cap. $3^{\circ}$; Art. 17) y subterráneas (Cap. $4^{\circ}$; Art.18 y ss). Por su especial naturaleza quedan divididas en minerales (Artículo15) y mineromedicinales (Artículo16) que son, respectivamente, "aquellas que contienen en disolución sustancias útiles para la industria en general, cualquiera que sea su naturaleza" y "aquellas que se aplican a la curación con sujeción a los reglamentos sanitarios". Adicionalmente, la Ley determina cuáles son las aguas de domino público, cuáles son las aguas con derecho de preferencia especial para su uso y/o aprovechamiento pero sin dominio sobre ellas y aquellas otras sin ese derecho de preferencia especial, y cuáles son las aguas de dominio privado, reservando a la Administración la tutela "para el buen orden en el uso y aprovechamiento de las aguas públicas" mientras que para las de dominio privado "la Administración se limitará a ejercer sobre ellas la vigilancia necesaria para que no puedan afectar a la salubridad pública ni a la seguridad de las personas y bienes" ${ }^{31}$.

Como se desprende de los Artículos 18 y 22, la Ley sigue el principio jurídico de la accesión al atribuir, en su Artículo 18, la plena propiedad de las aguas subterráneas al dueño de un predio que en él las hubiera obtenido por medio de pozos ordinarios, respondiendo así a la tradición del Derecho Romano, (son pozos ordinarios según el Artículo 20 "aquellos que se abren con el exclusivo objeto de atender al uso doméstico o necesidades ordinarias de la vida y en los que no se emplea para la extracción de agua otro motor o aparato que el hombre"- pozos, por tanto, de pequeña entidad-), mientras que sigue el principio jurídico de la ocupación -al dar carácter de res nullius a las aguas aún no alumbradas- (diferente, en este caso, al planteamiento del Derecho Romano) al atribuir, en su Artículo 22, al alumbrador "la plena propiedad a perpetuidad de las aguas subterráneas ${ }^{32}$, sin per-

31 Título V; Cap. XII “De la policía de las aguas", Arts. 226 y 227, respectivamente.

32 El hecho de que las aguas subterráneas fueran de dominio privado de quien las alumbrara, con independencia de la calificación del terreno donde se perforara, aun teniendo que contar con el cumplimiento, en su caso, del Artículo 25, Concesiones de terrenos públicos para alumbrar aguas, y que la Ley, además, dejara sin control los caudales a obtener, en los casos de alumbramientos por pozos artesianos, socavones y galerías, obedecía al hecho de la dificultad, en aquellos momentos, para determinar puntos de existencia de aguas subterráneas y de poder extraerlas en cantidades apreciables. Así lo ven autores como Martín-Retortillo, S.: "Derecho de aguas" (1997) Ed. Civitas, S.A. Madrid; pp.136-137: "existiendo un auténtico des- 
der su derecho "aunque salgan de la finca donde vieron la luz, cualquiera que sea la dirección que el alumbrador quiera darles mientras conserve su dominio", tanto para pozos ordinarios en el propio predio, como para las aguas halladas mediante pozos artesianos, socavones y galerías en cualquier terreno, con la limitación, en este caso, de no distraer o apartar aguas de su corriente natural. Según Gallego Anabitarte 33 "por pozo artesiano, (o socavón o galería) se entendió todo pozo que no era ordinario, es decir, que empleaba artefactos y maquinaria de extracción de agua distinto de la fuerza humana"

La Ley establece un derecho de preferencia especial para el uso y/o aprovechamiento de aguas que llegan a un predio privado directamente por la lluvia que cae sobre el mismo, ya que la Ley considera en su Artículo $1^{\circ}$ que "pertenecen al dueño del predio mientras discurran por él", pudiendo acopiarlas "utilizando cualquier tipo de ingenio, pero con la limitación de no perjudicar al público ni a terceros". Por tanto, la propiedad queda, en este caso, limitada a las aguas que pudiera acopiar, mientras que las que circularan por su predio, una vez caídas en él, sólo podrían ser usadas y/o aprovechadas en éste, no habiendo en este caso dominio de las aguas sino, más bien, efectivamente, "un derecho de preferencia especial para usarlas y/o aprovecharlas" ${ }^{34}$. (En las páginas 23-24 se analizará comparativamente este Art. $1^{\circ}$ con su correspondiente de la Ley de 1866). Este

conocimiento de la interconexión entre aguas subterráneas y aguas corrientes, lo que las daba a aquellas un carácter marginal" y del Saz, Silvia (UNED): "Aspectos jurídicos de las aguas subterráneas”; Serie D; núm.1; Fundación Marcelino Botín; pág.69: "Las aguas subterráneas quedaron excluidas de la declaración de dominio público al considerarlas una cuestión menor, además de la creencia de que eran de peor calidad que las superficiales y poco recomendables para el consumo humano". De aquí la modificación que, a este respecto, se hace en la Ley de Aguas de 2 de agosto de 1985, cuando los conocimientos hidrológicos habían avanzado mucho y la tecnología de perforación de pozos y de extracción de aguas subterráneas permite ya la obtención de grandes caudales de aguas subterráneas. En el mismo documento "Problemas la legislación sobre aguas subterráneas en España: posibles soluciones" pp.16 y 17, Moreu Ballonga expone que "el TS y la mayoría de la Doctrina no han acertado a explicar así las cosas y más bien han deducido de esta normativa que las aguas subterráneas pertenecían como regla general al dueño del terreno donde se alumbraban (principio de accesión en todo caso). Concepción errónea sin inconvenientes prácticos en la mayoría de supuestos en que el alumbrador era el mismo dueño del terreno, y que, en todo caso, como tal concepción errónea, presentaba en forma globalmente deformadora el conjunto del sistema legal".

${ }_{33}$ Gallego Anabitarte, A.; Menéndez Rexach, A. y Díaz Lerma, J.M. "El Derecho de aguas en España". Centro de Publicaciones del Ministerio de Obras Públicas y Urbanismo. Madrid, 1986. Tomo I. pp. 436-437.

34 Alonso Moya, F. (Abogado del Estado): "Sobre las aguas de dominio público $y$ de dominio privado", 1951, pp 29 a 73. https://dialnet.unirioja.es/descarga/articulo/2111865.pdf

(C) UNED. Revista de Derecho UNED, núm. 27, 2021 
Art. $1^{\circ}$, en su párrafo $2^{\circ}$ "reputa como aguas pluviales a aquellas que proceden inmediatamente de las lluvias" y a este respecto Melchor de Palau i Catalá ${ }^{5}$ introduce un análisis temprano de la Ley con una inteligente crítica, entre otras, a esta definición dada para aguas pluviales por el $2^{\circ}$ párrafo del citado Art. $1^{\circ}$, al opinar que las aguas de lluvia caídas en un predio deberían conservar el carácter pluvial mientras no salieran del predio o cauce recipiente en que cayeron, pero entrando al pasar a otro terreno en la categoría de aguas corrientes, por analogía con las aguas de origen de manantial que contempla el Art. $5^{\circ}$.

En efecto, este Artículo $5^{\circ}$ de la Ley dispone que las aguas que nacen en un predio, público o privado, continua o discontinuamente, "pertenecen, mientras discurren por los mismos predios, al dueño respectivo para su uso y aprovechamiento", pero sin ostentar éste su dominio, tratándose, también en este caso, de un derecho que otorga una preferencia especial para su uso y/o aprovechamiento, pasando a ser públicas las aguas excedentarias no aprovechadas cuando salen del predio donde nacieron.

De aquí que la Ley permite la existencia de un régimen jurídico doble con distinto tratamiento: uno, para las aguas superficiales públicas, que quedan intervenidas por la Administración, y otro, para las subterráneas y superficiales privadas. En esta línea, las aguas de lluvia quedan sometidas, precisamente, a este doble régimen jurídico en función del terreno donde caigan en virtud del criterio de accesión. En opinión de Gay de Montellá y Massó Escofet, -apoyándose en Laurent, François, que considera que "las aguas pluviales no eran res nullius puesto que al caer en un predio debían ser consideradas parte de ese predio"-, los Artículos $1^{\circ}$ y $2^{\circ}$ de la Ley derivan de este criterio ya que, respectivamente, exponen que: "pertenecen al dueño de un predio las aguas pluviales que caen en el mismo mientras discurran por él" y "son de dominio público las aguas pluviales que discurran por barrancos y ramblas, cuyos cauces sean del mismo dominio público"36, siendo, pues, un derecho de accesión, en contra

35 de Palau i Catalá, "Ley de 13 de junio de 1879. Comentarios referencias y notas críticas". Ed. Teixidó i Parera, 1879 Barcelona-Madrid, pp. 91 y ss. Palau entiende que "la definición de aguas pluviales dada por el Art.1 $1^{\circ}$ no es del todo exacta como lo prueba el Art. siguiente (Art.2) al hablar de aguas pluviales que recorren cauces de dominio público", opinando que "análogamente a lo que de las aguas manantiales se desprende, deberían conservar el carácter pluvial mientras no salieran del predio o cauce recipiente en el que cayeron, entrando al pasar a otro terreno a la categoría de aguas corrientes".

36 Gay de Montellá, R y Massó Escofet, C. "Tratado de la Legislación de Aguas públicas y privadas". Tomo I: "Legislación Fundamental" y Tomo II "Legislación 
de la opinión de Daviel, Alfred ${ }^{37}$, al que citan, que las considera un derecho de ocupación al considerar las aguas pluviales res nullius. Situación ésta ya anteriormente expuesta para el caso de la Ley de Aguas de 1866.

La Ley de 1879 aparte de distinguir entre estos dos regímenes jurídicos, público y privado, hace distinción entre tres conceptos: dominio, uso y aprovechamiento. Ya la Comisión redactora de la Ley, en la exposición de motivos, justifica la base de los argumentos que la ha llevado a establecer el dominio público de las aguas, lo que también la obliga a establecer la diferenciación entre dominio de las aguas, su uso y su aprovechamiento como conceptos diferenciados, al tiempo que se mantiene dentro, como ya expuso, de las tradiciones consuetudinarias, exponiendo lo siguiente:

"La Comisión ha partido del principio sentado por el Gobierno y aceptado sin contradicción alguna por la opinión pública del país, de que todas las corrientes naturales de agua eran de dominio público, recogido ya en el $R$. D. de 29 de abril de 1860, que exigía la Real autorización para llevar a cabo cualquier empresa de interés público o privado que tuviera por objeto el aprovechamiento de las aguas de los ríos, riachuelos, rieras, arroyos o cualquier otra clase de corrientes naturales, sea cual fuere su denominación". Y continúa la Comisión exponiendo que "Juzga indispensable determinar los caracteres generales que separan y diferencian el aprovechamiento del dominio", definiendo éste como "derecho absoluto e ilimitado sobre la cosa, y el aprovechamiento como derecho limitado, sujeto a las condiciones impuestas por quien lo concede, y que sólo autoriza para usar en la forma y para el objeto concedido".

Ante el análisis de la Ley y de la lectura de la Exposición de motivos de la Comisión, conviene diferenciar, en cuanto a títulos para la utilización de las aguas, entre dominio público, dominio privado, uso y aprovechamiento, conceptos estos dos últimos, uso y aprovechamiento, que se reproducen frecuentemente en la Ley con cierta polisemia, (como concepto jurídico en el ámbito de las aguas, como aprovechamiento de aguas y como fin al que se destina el agua) habiendo sido estudiados por diversos autores, para lo que parten del estudio de la propia Ley y de la exposición de motivos redactada por

Complementaria". Ed. Casa Editorial Bosch; Barcelona-1956, pp 59 a 69 del Tomo I. Citados por Álvarez Fernández, M. en "El abastecimiento de agua en España". Ed. Civitas; 2004. pp.46-47.

37 Daviel, Alfred; "Des Eaux et Traité de la législation et de la practique des cours d'eaux”. Ed.: Charles Hingray, Libraire-Éditeur; 3ª Ed. Paris 1845.

(c) UNED. Revista de Derecho UNED, núm. 27, 2021 
la Comisión encargada de este proyecto que contempla la gestación de la Ley de Aguas de 1879.

Abellán Contreras, F.J. ${ }^{38}$, contempla la diferencia entre el dominio y el aprovechamiento y sigue la línea de la Comisión en cuanto a que el dominio, o derecho de propiedad, es un derecho real que atribuye a su titular la facultad de gozar y disponer de una cosa, o bien disponer sin más limitaciones que las establecidas por la Ley, respondiendo al principio jurídico de que es lícito hacer todo aquello que a uno aprovecha y que a nadie daña. El aprovechamiento también lo ve en la misma línea que la Comisión como un derecho limitado sujeto a las condiciones del que lo concede. Álvarez Fernández, M. ${ }^{39}$ sigue también esta línea exponiendo que "el uso de las aguas de dominio privado no es más que una de las facultades inherentes al derecho de la propiedad, siendo posible el aprovechamiento de las mismas por persona distinta de su propietario. En el caso de aguas de dominio público, si bien la Administración puede utilizar por sí misma tales aguas, con carácter general, el aprovechamiento se realiza por un administrado o por organismo distinto a la propia Administración del Estado, que se sujetarán al régimen general de las utilizaciones demaniales". El tercer elemento que se introduce en el Régimen de utilización de las aguas es el Uso, término algo confuso ya que la Exposición de motivos distingue dos tipos de Aprovechamientos: un primer tipo que define como aquellos "aprovechamientos que son inherentes a la naturaleza pública del agua y que no exigen autorización o concesión especial puesto que se limitan a USAR de las corrientes sin consumirlas ni impedir iguales aprovechamientos por parte de otros" y, por otro lado, otro tipo de Aprovechamiento que establece como aquellos "que consumiendo el agua o impidiendo que otros la aprovechen en el mismo punto y de la misma manera, exigen concesiones especiales por parte del poder encargado de mantener el orden y procurar la armonía y el disfrute de toda clase de aprovechamiento público". En el primer caso, la ley acoge el Uso de las aguas públicas en el Articulado (Artículos 126 a 146) del Capítulo X, Título IV, bajo el epígrafe "de los aprovechamientos comunes de las aguas públicas" que divide en tres Secciones en función del Aprovechamiento (Uso) que se vaya a dar a las aguas: "Servicio doméstico, agrícola y fabril"; "para la

38 Abellán Contreras, F.J "El Aprovechamiento de las aguas en la Ley de 13 de junio de 1879. Trayectoria de un texto legislativo a la luz de la optimización y eficacia de los recursos hídricos". pp.691-692. Universidad de Alicante; 2014 (última revisión febrero, 2015). Congresos Universitat Politècnica de València. http://ocs.editorial.upv. es/index.php/ISL/ISL2014/paper/view/148

39 Álvarez Fernández, Mónica, Universidad de Oviedo: op.cit: "El abastecimiento de agua en España". Ed. Civitas; 2004. pp. 57-58. 
pesca" y "navegación y flotación". De aquí, la superposición de ambos términos, uso y aprovechamiento, con alguna contradicción, entre lo establecido en la Exposición de motivos y el citado Articulado en la propia Ley, que se analizará a continuación. En el segundo caso, la Ley acoge la característica de este tipo de Aprovechamiento en el Articulado (Artículos 147 a 225) del Capítulo XI del Título IV, bajo el epígrafe "de los aprovechamientos especiales de las aguas públicas", que divide en siete Secciones en función del objeto de los Aprovechamientos a los que se destinen las aguas y que jerarquiza y exige autorización: "abastecimiento a poblaciones"; "abastecimiento de ferrocarriles"; "riegos"; "canales de navegación"; Barcas de paso y establecimientos industriales" y "viveros o criaderos de peces".

Entrando en el primer tipo, "de los aprovechamientos comunes", que es el que interesa en primer lugar, el término $<$ Uso $>$ hay que contemplarlo como el disfrute de una cosa, el servirse de ella y, en el caso que nos ocupa, lo sería sin alterar sus propiedades. Para Gay de Montellá y Massó Escofet "el Uso común de las aguas públicas es un verdadero derecho público, pero que no da derecho a acción civil alguna ni autoriza para recabar una indemnización en caso de menoscabo o reducción de uso, teniendo como límite preceptos de policía que normalizan su ejercicio frente a los servicios de Sanidad, Higiene y Seguridad que competen al poder público no difiriendo estos requisitos para ninguno de los usuarios, que quedan sometidos a Leyes y Reglamentos con sus correspondientes limitaciones"; el Uso está, pues, regido por prescripciones que no difieren para ninguno de los usuarios y que están taxativamente emanadas de la legislación correspondiente. Y continúan exponiendo estos Autores que "la Ley, en general, no condiciona a ningún requisito previo el ejercicio de los usos comunes, en los cuales no hay merma de caudales ni se impide iguales usos por parte de otros, sometiéndose, por tanto, el Uso a prescripciones invariables a las que han de sujetarse los usuarios; sin embargo, en los Aprovechamientos los órganos administrativos fijan para cada uno de los peticionarios diferentes condiciones y modalidades de otorgamiento en función de las circunstancias que pueden ofrecer las corrientes, las condiciones topográficas, los cultivos a los que ha de aplicarse, etc. y crea un verdadero derecho sobre una cosa pública"40. En este caso,

${ }^{40}$ Gay de Montellá, R y Massó Escofet, C. "Tratado de la Legislación de Aguas públicas y privadas". Tomo I: "Legislación Fundamental" y Tomo II "Legislación Complementaria". Ed. Casa Editorial Bosch; Barcelona-1956 pp 325 a 333. y "Tratado de la Legislación de Aguas públicas y privadas, comentarios a los preceptos de la ley de Aguas, a la legislación complementaria y a la jurisprudencia" 2a Edición 1949, Ed. Casa Editorial Bosch; Barcelona. Epígrafes 170 a 173 y 176 a 178, Capítulos XIX y $\mathrm{XX}$, respectivamente. 
pues, los órganos Administrativos concedentes tienen la facultad de fijar y de exigir al peticionario modalidades y condiciones peculiares para cada petición. Estos Autores consideran que las aguas pueden ser aprovechadas en base a tres títulos: "por el uso común, por el derecho de propiedad y por concesión del poder público representado por la Administración del Estado"41.

Pero conviene ir un paso más allá de lo expuesto en la Ley, en su Título IV, en lo concerniente a la clasificación de las aguas públicas en "Aprovechamientos Comunes de las Aguas Públicas" y "Aprovechamientos Especiales de las Aguas Públicas" según destino (o uso) de las mismas, ya que, en mi opinión, como se acaba de esbozar, la Ley está a falta de una mayor rigurosidad en cuanto a la coherencia entre lo definido para los dos tipos expuestos de Aprovechamientos que contempla en su Exposición de motivos, y lo que determinan los Artículos que en la Ley contemplan estos dos tipos de Aprovechamientos citados.

Pues bien, la Ley no encaja a la perfección con las conceptualizaciones que vierte la Exposición de Motivos, ya que el concepto Uso que hace referencia a la utilización del agua sin consumo de la misma y, consecuentemente, no impidiendo que otros la utilicen en la misma forma y con las mismas características fisicoquímicas, es recogido en la Ley bajo el epígrafe citado "de los aprovechamientos comunes del agua pública", de forma que algunos de sus correspondientes Artículos contemplan Usos en los que se produce consumo. Inversamente, el concepto de aprovechamiento que en la Exposición de Motivos hace referencia a consumo de agua para diferentes fines, impidiendo que otros la aprovechen en el mismo punto y de la misma manera, es recogido en la Ley bajo el epígrafe "de los aprovechamientos especiales de las aguas públicas", pero de forma que algunos de su correspondientes Artículos hacen referencia a aprovechamientos que no consumen agua. En mi opinión el término Aprovechamiento es genérico y la Ley lo contempla como determinante de Uso sin consumo y de Uso con consumo. De aquí que como "Aprovechamientos comunes" (Arts.126 a 146) la Ley haga referencia a Usos sin consumo (domésticos -aunque en este caso el Art.127 permita extraer algunos pequeños caudales- pesca y navegación y flotación), mientras que como "Aprovechamientos especiales" (Arts. 164 a 225) la Ley implica Usos con consumo (abastecimiento a poblaciones, a ferrocarriles y riego, Secciones, $2^{\mathrm{a}} ; 3^{\mathrm{a}}$ y $4^{\mathrm{a}}$

41 Gay de Montellá, R y Massó Escofet, C. op.cit. “Tratado de la Legislación de Aguas públicas y privadas". Tomo I: "Legislación Fundamental" y Tomo II "Legislación Complementaria” pp. 325 y ss. del Tomo I. 
del Capítulo XI) y Usos sin consumo (canales de navegación; barcas de paso y establecimientos industriales -estos últimos en base a los Arts. 220 y 221 - y criaderos de peces), aunque todos ellos precisan concesión o autorización.

Por tanto, y como conclusión, debería establecerse para los conceptos expuestos, una matriz con los conceptos: dominio; derechos de preferencia para uso y/o aprovechamiento; uso o aprovechamiento común sin consumo y uso o aprovechamiento común con pequeño consumo y, por otro lado, uso o aprovechamiento especial con consumo y uso o aprovechamiento especial sin consumo; matriz en la que se contemplan todos los tipos que realmente trata la Ley en la que quedan bien tipificados y conceptualizados los usos o aprovechamientos según el comportamiento que tengan en su destino. Para Pérez Pérez, $\mathrm{E}^{42}$. se pronuncia en esta línea y entiende que "el régimen jurídico de la utilización de las aguas podría configurarse a partir de los conceptos de derecho subjetivo y de servicio público, por lo que los aprovechamientos comunes (beber, lavar, pescar, navegar) deberían ser atendidos mediante los oportunos servicios públicos, mientras que los demás aprovechamientos, (aprovechamientos especiales en la Ley) que tienen carácter excluyente, tendrían que derivar de un derecho subjetivo reconocido a un titular especifico, individual o colectivo". Pero siendo este autor un defensor de la unidad del sistema hídrico, "no aprueba la separación de los campos iuspublicístico y iusprivatístico en esta materia" ya que entiende que "la utilización de las aguas debe ser conjunta, múltiple y coordinada".

La Ley de Aguas de 1879, aunque, como se ha expuesto, sigue los mismos principios fundamentales y espíritu normativo que su antecesora de 1866, manteniendo también similar estructura, introdujo algunas variaciones tales como la ya citada segregación de todo el articulado correspondiente a las aguas marinas y la introducida por el Art. $1^{\circ}$ en el que a lo dispuesto por su antecesora, la Ley de Aguas de 1866, -referente a las construcciones que el dueño de un predio pueda construir en él para recoger las aguas pluviales que en el mismo caigan- añade: “...emplear cualquier otro medio adecuado, siempre que con ello no cause perjuicio al público ni a terceros", ex-

42 Pérez Pérez, E. "Legislación y Administración del Agua en España (criterios para su reforma)". Ed.: Editora Regional de Murcia; 1981; p-65 y 116. Este autor, en el ámbito organizativo, postula la reducción de diferentes Administraciones en la gestión del agua yendo hacia una Autoridad única y, por otro lado, defiende la utilización del agua como un sistema integral de recursos que comprende las tomas, los usos y los vertidos como un todo unitario que incide en el medio ambiente, adelantándose así, a este respecto, en veinte años, a la Directiva Marco del Agua del año 2000, (2000/60/CE, de 23 de octubre).

(c) UNED. Revista de Derecho UNED, núm. 27, 2021 
tendiendo de una manera genérica los elementos constructivos que antes quedaban exclusivamente determinados por "estanques, pantanos, cisternas o aljibes". Por otro lado, este mismo Art. $1^{\circ}$ de la Ley de 1879 limita el origen de las aguas de lluvia para que el dueño del predio al que éstas lleguen tenga derecho de preferencia para su uso o aprovechamiento (puesto que análogamente a la anterior Ley "estas aguas le pertenecen mientras discurran por su predio"), al exponer que son aquellas "que caen en el mismo predio", pero añadiendo que "se reputan como aguas pluviales para los efectos de esta Ley las que proceden inmediatamente de las lluvias". Sin embargo, la anterior Ley de 1866, en su Art.30, establecía, con respecto a las aguas de lluvia, que son "las que caen o se recogen en el predio", sin hacer, pues, referencia a la inmediatez de la lluvia con respecto a la entrada de ésta en el predio, generando así una ambigüedad pues recoger puede hacer referencia a la ampliación de la procedencia de las aguas una vez ya caídas o bien a las acopiadas en los medios que cita, y además, en cualquier caso, hayan caído o no directamente en el propio predio. Por otro lado, la Ley de Aguas de 1879, define el pozo ordinario lo que no hacía la anterior Ley de 1866 y limita, con respecto a ésta, los caudales a extraer por la vía de conceptuarlos como únicamente dirigidos a cubrir las necesidades domésticas y a extraerlos con la única fuerza del hombre, mientras que su antecesora permitía la extracción con cualquier clase de aparato.

Así, pues, el objetivo de quienes comenzaron la redacción de la Ley de Aguas de 1879 de que ésta fuera la adaptación de la Ley de 1866 a las posteriores leyes de Obras Públicas del sistema político de la Restauración, se acabó sobrepasando ya que, según Nieto García "al tiempo, y un tanto subrepticiamente (el fenómeno nunca ha sido puesto suficientemente de relieve por la doctrina), transformaron también el régimen de aguas subterráneas, derogando Ley de Minas de 4 de marzo de $1868^{\prime \prime} 43$.

La Ley se ocupó también, al igual que su antecesora, de legalizar las situaciones fuera de la ley por medio de su Artículo 149, que determina que el que "durante veinte años hubiese disfrutado de un aprovechamiento de aguas públicas, sin oposición de la Autoridad o de terceros, continuará disfrutándolo aun cuando no pueda acreditar que obtuvo la correspondiente autorización", aunque, sin embargo, no pone término a su eficacia. Este Artículo reproduce el Artículo 194 de la Ley de Aguas de 1866 que ya admitió esta posibilidad de la prescripción como título legítimo para llevar a cabo el aprovecha-

${ }^{43}$ Nieto García, A. "Aguas subterráneas: subsuelo árido y subsuelo hídrico"; Revista de Administración Pública núm. 56; Mayo/Agosto, 1968; pág. 26. 
miento de aguas públicas. También el Código Civil de 1889 opera en esta misma línea en su Artículo 409, determinando que "el aprovechamiento de las aguas públicas sólo se adquiere por concesión administrativa o por prescripción de veinte años". La Ley de Aguas de 1866 dio, pues, una salida a situaciones existentes de facto, que mantiene la Ley de Aguas de 1879, que deja sin cerrar, como se acaba de decir, el momento de inicio a partir del cual debe comenzar a contar el plazo. Por tanto, las Leyes de Aguas de 1866 y 1879 y el Código Civil de 1889 contemplan esta forma de adquisición del disfrute de un aprovechamiento de aguas públicas, pero siempre se aplica al disfrute de aprovechamientos que se hubieren mantenido durante veinte años, sin hacer nunca referencia al dominio de las aguas que generan esos aprovechamientos.

A pesar del gran avance legislativo que logró la Ley de Aguas de 1879 con su correspondiente regulación de éstas, aún se presentaban problemas a los que no conseguía dar una solución satisfactoria y que se derivaban de contradicciones internas de algunos de sus preceptos e, incluso, del tratamiento de algunos conceptos relativos a la propiedad de las aguas. Ejemplo de ello es el hecho de que pese a conceder la propiedad de las aguas al alumbrador de éstas en cualquier terreno privado o público -en este último caso con la correspondiente autorización- por medio de pozo artesiano, socavón o galería, el alumbrador queda en posición exenta ante el dueño de un terreno privado que queda en situación de desprotección para con su terreno y de participación en los resultados obtenidos por el alumbrador, forma así legislada, en opinión de Moreu Ballonga, para estimular la iniciativa privada ${ }^{44}$. En cualquier caso, sin embargo, el dueño de cualquier terreno puede alumbrar aguas en el mismo, por medio de este tipo de obras, apropiándose plenamente de ellas, en su condición de alumbrador, con la limitación de no distraer o mermar aguas públicas o privadas destinadas a un servicio público o a un aprovechamiento privado con derechos ya adquiridos, de aquí que el precepto marque unas distancias mínimas a otros puntos de extracción (Artículo 23).

Al igual que ocurriera con la Ley de Aguas de 1866, el Reglamento de la Ley de Aguas de 1879 no llegó a materializarse, apare-

44 Moreu Ballonga, J.L. Ponencia sobre "la difícil distinción entre aguas públicas y privadas y sus consecuencias". Jornada de "Sostenibilidad en los usos agrícolas del agua" organizada por el Consejo General de los Colegios oficiales de Ingenieros Técnicos Agrícolas. 23, junio, 2017. En referencia a su obra "Aguas públicas y privadas", 1996, manifestando haber evolucionado hacia una posición de defensa de las aguas privadas. https://www.youtube.com/watch?v=0F_dMRK-upI 
ciendo normas sustitutivas de menor rango que trataban de resolver los principales problemas que se iban presentando publicándose dos Reales Órdenes: la R.O. del 5 de junio de 1883 "sobre alumbramiento de aguas subterráneas en terreno de dominio público y del Estado" que dispone, en su Artículo 6, "que la tramitación en ella señalada es también aplicable a las solicitudes para alumbrar aguas subterráneas en terrenos de propios o del común de los Pueblos", por lo que se afirman los derechos al dominio de las aguas subterráneas del propietario del suelo, que en consecuencia puede autorizar a terceros a que las busquen en su terreno y pueda también él utilizarlas posteriormente, lo que modera el Artículo 22 de la Ley en cuanto a los derechos del alumbrador, y la R.O. del 2 de mayo de 1891, que aportaba disposiciones aclaratorias a la espera de una nueva Ley. La Ley de Bases de 11 de mayo de 1888 recoge esta problemática, y aun siendo posterior al proyecto de Código Civil de 1851 -conocido como Proyecto García Goyena- fue el germen del Código Civil que se publica por R.D. de 6 de octubre de 1888 y que genera una discusión acerca de su adecuación o no a la citada Ley de Bases, lo que generó una segunda edición del Código Civil promulgada por R.D. de 24 de julio de 1889.

Por tanto, la Ley de Aguas de 13 de junio 1879 es una ley que regula todo el ámbito de las aguas terrestres dando un doble tratamiento jurídico a las aguas derivado de un régimen Privatista, para las subterráneas, en tanto que privadas, y de otro, Administrativista para las públicas, discriminando las aguas, este último régimen, en función de sus usos y de sus aprovechamientos. No es, pues, una ley que concreta sólo su objetivo en el ámbito del aprovechamiento de las aguas públicas, sino que abarca toda la materia de aguas, buscando lograr el mejor aprovechamiento global de las aguas existentes por lo que fomenta el interés por los aprovechamientos colectivos de aguas superficiales a los que "dota de una gestión participativa a través de Comunidades de Regantes que, mediante reglas sólidas fijadas para la ordenación de los aprovechamientos, logran una correcta distribución y gestión del agua"45. La Ley regula, así mismo, los derechos y deberes que se derivan del dominio de las aguas, de su uso y de su aprovechamiento velando por una buena utilización de éstas, a las que contempla como riqueza nacional al servicio de las necesidades generales de todo el País, por lo que deben de ser usadas y aprovechadas de la manera más eficiente posible para lo que llega a restringir derechos dominicales en beneficio del interés general.

45 Pérez Pérez, E. "Estudios jurídicos sobre la propiedad, aprovechamientos y gestión del agua”. MOPT-1993; pp.30-39. 


\section{EL CÓDIGO CIVIL DE 24 DE JULIO DE 1889 Y SU RELACIÓN CON LA LEY DE AGUAS DE 1879.}

El Código Civil sigue la Ley de Aguas de $1879^{46}$, pero tratando de dar solución a los problemas que se planteaban bajo los preceptos de ésta, partiendo, para ello, de una distinción entre aguas de dominio público y de dominio privado que deja clara y contundentemente establecida en sus Artículos 407 y 408 del Capítulo I, "de las aguas", del Título IV, "de algunas propiedades especiales". El citado Capítulo I abarca los Artículos 407 a 425, y está dividido en cinco subsecciones, si bien el Artículo 350 ya se ocupaba de determinar que "el propietario de un terreno es dueño de su superficie y de lo que está debajo de ella, y puede hacer en él las obras, plantaciones y excavaciones que le convengan, salvas las servidumbres, y con sujeción a lo dispuesto en las leyes sobre Minas y Aguas y en los reglamentos de policía". Por tanto, esta declaración privatista quedaba limitada por lo dispuesto, a este respecto, en las Leyes de Minas y de Aguas y en los Reglamentos de policía, sometiendo, por tanto, a la legislación especial de Aguas el comportamiento de un propietario de un terreno en lo tocante a las aguas en éste, con lo que la primera parte del precepto queda reducida a muy poca cosa. Las subsecciones citadas se ocupan, respectivamente, de: Del dominio de las Aguas; Del aprovechamiento de las Aguas Públicas; Del aprovechamiento de las Aguas de dominio privado; De las Aguas Subterráneas; y Disposiciones Generales. El Artículo 414, de la Sección 3", "del aprovechamiento de las aguas de dominio privado" dispone que "nadie puede penetrar en propiedad privada para buscar aguas o usar de ellas, sin licencia del propietario", incidiendo el Artículo 417, de la Sección 4a, "de las aguas subterráneas", en que "sólo el propietario de un predio, u otra persona con su licencia, puede investigar en él aguas subterráneas y en el caso de predio de dominio público, con licencia administrativa". Sin embargo, el Artículo 418 siguiente, inscrito, también, en esta misma Sección $4^{\text {a }}$, dispone que "las aguas subterráneas, conforme a la Ley Especial de Aguas, pertenecen al que las alumbró". Finalmente, el Artículo 425, último de los de este Capítulo dedicado a

46 Nieto García, A.: op. cit. "Aguas subterráneas: subsuelo árido y subsuelo hídrico". pp.27-28: "Para una mentalidad moderna carece de sentido la superposición normativa que representa el Código Civil respecto a las Leyes administrativas especiales de 1866 y de 1879. El Código Civil, de acuerdo con la Base 10a (de la Ley de Bases) dedica pocos artículos a las aguas y aún éstos, en su mayoría, son inútiles porque, o bien se trata de meras repeticiones de la Ley (que ninguna utilidad ofrecen) o bien introducen nuevos principios que, por desgracia, nada aclaran", concluyendo el profesor Nieto que "se dejó pasar una oportunidad para afrontar los problemas de base en relación al binomio alumbrador-dueño del terreno”.

(C) UNED. Revista de Derecho UNED, núm. 27, 2021 
las Aguas, inscrito, por tanto, en la Subsección $5^{a}$, última de éstas, convierte en supletoria la Ley de Aguas con respecto al Código Civil al disponer que "en todo lo que no esté expresamente prevenido por las disposiciones de este Capítulo, se estará a lo mandado por la Ley Especial de Aguas", que remacha nuevamente el Artículo 563. El objeto coincidente de la regulación que ambas Normas, Código Civil y Ley de Aguas de 1879, con sus correspondientes identidades o contradicciones de los preceptos de una y otra Norma, ha llevado a algunos Autores a delimitar el objeto y estudio de una y otra disciplina, <corroborando la competencia del Derecho Civil en todo lo referente a la propiedad de las aguas y su distinción de la propiedad pública, mientras que será propio del Derecho Administrativo defender y reivindicar las aguas del dominio público y regular la participación (usos o aprovechamientos) que en su disfrute puede concederse a los particulares $>^{47}$.

Por tanto, esta materia de aguas queda recogida por tres legislaciones que se complementarán: Ley de 13 de junio de 1879, de Aguas; Ley de 7 de mayo de 1880, de Puertos, en cuanto a aguas marinas, y por el Código Civil de 1889. Consecuentemente, las Aguas tienen una Ley General, que es el Código Civil y dos leyes especiales: la de 13 de junio de 1879, de Aguas y la de 7 de mayo de 1880, de Puertos.

Pero de esta doble regulación en la materia de aguas terrestres, Ley de Aguas de 1879 y el Código Civil, se han derivado unos inconvenientes generados por supuestos de posibles contradicciones entre ambas regulaciones, destacando el Profesor Martín-Retortillo la acomodación de ambas Normas a los principios políticos respectivos, y "éstos son notoriamente diferentes, una muy notable potenciación de lo público en la Ley de 1879 y más individualista en el Código Civil, habiendo cambios de sistemática y de concepto que, en su aplicación, llevaron a cabo los Tribunales y la propia Administración" ${ }^{48}$. En definitiva, se reflejó un carácter contradictorio de numerosas resoluciones judiciales y disposiciones administrativas, especialmente, en lo referente al alcance y extensión de las aguas públicas y privadas.

Así, pues, la diferente sistematización y, en ocasiones, conceptualización, entre aguas de dominio público y de dominio privado, en la Ley de Aguas de 1879 y en el Código Civil, hizo surgir interpretaciones distintas derivadas de los preceptos concretos de uno

47 Álvarez Fernández, Mónica, Universidad de Oviedo: "El abastecimiento de agua en España". Ed. Civitas; 2004. op. cit p. 51.

48 Martín-Retortillo Baquer, S.: "El Derecho de Aguas". Ed. Civitas, 1997; pp.112-ss. 
y de otro. Así, mientras una opinión mantenía que para todas las aguas que nacían en los predios privados (salvo manantiales que fueran cabecera de río) podía darse un derecho de propiedad pleno, otras opiniones se inclinaban por limitar el derecho de estas aguas, que no constituían corrientes naturales, a un aprovechamiento de las mismas. Otras opiniones, en posiciones más eclécticas, condicionaban, en base al Artículo $5^{\circ}$ de la Ley de Aguas, el dominio de estas aguas, nacidas en predios privados, a su aprovechamiento, de forma que si el dueño no las aprovechaba pasaban a ser públicas. Parecía que se impusiera la tesis del aprovechamiento sobre la del dominio, pero, según otros, el Código Civil influyó para que se impusiera la tesis del dominio.

Posteriormente, en 1988, el Tribunal Constitucional, ha hecho referencia a los conceptos que contenía la Ley de Aguas de 1879 y el Código Civil, en el ámbito de las Aguas, en sentencia 227/1988, de 29 de noviembre, remontándose a los preceptos de la Ley de Aguas de 1879, derogada por la Ley de Aguas de 1985, que es objeto de impugnación ${ }^{49}$. El TC se refiere al dominio privado sobre determinadas aguas superficiales según las contempla la Ley de Aguas de 1879. Así, en su Fundamento 6 de esta Sentencia, manifiesta que el dominio privado sobre determinadas aguas superficiales se limitaba a una facultad de apropiación o de aprovechamiento privativo preferente, accesoria de la propiedad del predio en que nacen, y en cuanto a las aguas subterráneas distingue entre pozos ordinarios -de pequeña entidad-y los pozos artesianos, los de socavones y las galerías, de mayor importancia, atribuyendo al dueño de un predio en plena propiedad las que en él hubiera obtenido por medio de pozos ordinarios, no aludiendo la Ley, en este caso de pozos ordinarios, al alumbrador que, sin embargo, deviene en una figura central en los otros pozos de mayor importancia. En su Fundamento 12 hace referencia, obiter dictum, al derecho de propiedad, "al ser tales aguas de la propiedad de los dueños de los predios donde se hallan los manantiales de los que brotan, en el caso de las superficiales, o de quienes las hayan alumbrado, en el caso de las subterráneas".

49 Recurso de inconstitucionalidad interpuesto por la Junta de Galicia, el Consejo de Gobierno de la Comunidad Autónoma de Baleares, el Gobierno Vasco y el Consejo de Gobierno de la Diputación Regional de Cantabria, en relación con la Ley 29/1985, de Aguas, y conflictos positivos de competencia planteados por el Gobierno Vasco en relación al R.D. 849/1986, de 11 de abril, por el que se aprueba el Reglamento del Dominio Público Hidráulico en desarrollo de la Ley de Aguas de 1985 y otros Reales Decretos y Órdenes en relación a ámbitos territoriales de los Organismos de Cuenca y de los Planes Hidrológicos. 
Por tanto, las aguas subterráneas, según la Ley de 1879, pueden clasificarse en aguas halladas y extraídas y en aguas halladas, pero no extraídas. En el primer caso pueden coincidir en la misma persona propietario del terreno y alumbrador pero la apropiación del agua se derivará de la condición de alumbrador. En cuanto al segundo caso, el Código Civil, en su Artículo 407.6. establece que son aguas de dominio público "las aguas subterráneas que existan en terrenos públicos", mientras que en el Artículo 408.3. dispone que son aguas de dominio privado "las aguas subterráneas que se hallen en estos predios de dominio privado". Álvarez Fernández ${ }^{50}$ recoge el pensamiento de Nieto García, de Guaita Martorell y de Moreu Ballonga. El primero entiende que "El sentido que el Código Civil atribuye al verbo hallar, ha sido objeto de atención especial. Nieto García, A. considera que este verbo, de significado anfibológico, se utilizó aquí en el sentido de <descubrir o alumbrar>, por contraposición a la expresión del Artículo 407.6 del Código Civil, <existan>, que, según este autor es inequívoca y referida a las aguas que estén bajo los predios de dominio público". Sin embargo, Guaita Martorell y Moreu Ballonga utilizan el término hallar en el sentido de existir ${ }^{51}$, concibiendo Moreu Ballonga "la adquisición de la propiedad de lo vacante de posesión por un acto jurídicamente suficiente y en las condiciones de la Ley". La controversia que se generaba, derivada de las diferentes interpretaciones de las legislaciones, iba en aumento a medida que, al tiempo, se incrementaban las necesidades de agua, recurriéndose a las aguas subterráneas cuyas técnicas de extracción iban avanzando, siendo capaces de extraer mayores caudales de los pozos construidos. Nieto García, A. ${ }^{52}$ considera la existencia de tres tipos de aguas subterráneas: las ya alumbradas y elevadas a la superficie, propiedad del que las alumbró; las no alumbradas (res nullius) y, finalmente, la masa líquida ya alumbrada, de donde procede lo elevado a la superficie, pero que aún está subterránea, por lo que falta establecer la relación jurídica que tiene el alumbrador con el caudal aún no extraído. De aquí, su opinión en relación a la legislación de Aguas de 1879, junto con la normativa que la complementa con posterioridad, R.O. de 5 de junio de 1883 y Código Civil

50 Álvarez Fernández, M. "El abastecimiento de agua en España”. Ed. Civitas; 2004). op. cit p. 57; Nieto García, Alejandro: "Aguas subterráneas: subsuelo árido y subsuelo hídrico"; p.28, en Álvarez Fernández, M. op.cit. p.57.

51 Guaita Martorell, A.: "Derecho Administrativo. Aguas, Montes, Minas". Ed. Civitas. 1982 Madrid, p. 194 y ss. y Moreu Ballonga, J.L. "Ocupación, hallazgo y tesoro” Ed. Bosch 1980, Barcelona. pp. 648-652; en Álvarez Fernández, M. op.cit “El abastecimiento de agua en España".

52 Nieto García, A. op. cit. "Aguas subterráneas: subsuelo árido y subsuelo hídrico” Ed. Cabildo Insular de Tenerife-Aula de Cultura; 1968; pp. 9-92. 
de 1889 , de que "el sistema es imperfecto por causa de las rudimentarias bases geológicas en que se apoya y por su complicación jurídica, resultado de una concepción patrimonial individualista de las aguas, que los autores han denunciado reiteradamente".

\section{INTENTOS DE MODIFICACIÓN DE LA LEY DE AGUAS DE 13 DE JUNIO DE 1879.}

La evolución económica y técnica van haciendo progresivamente más difícil que la Ley de Aguas resuelva los problemas que se van planteando. El desarrollo industrial y agrícola junto con el cambio tecnológico que comienza a darse en la extracción del agua subterránea como respuesta a los avances científicos en las técnicas de prospección, captación, transporte, almacenamiento y depuración van cambiando el contexto en el que se inscribía el nacimiento de la Ley, exigiendo un acomodo jurídico de ésta a la nueva realidad tecnológica y de demanda de agua. Así, el profesor Jordana de Pozas, pese a reconocer la calidad de la Ley vigente y no aconsejando "revisionismos a ultranza", señala que la reforma es "necesaria" por los importantes cambios sufridos relativos al agua y "oportuna porque todas las partes del ordenamiento jurídico del país han de guardar proporción, estar bien ensambladas y responder a la concepción presente del mundo y de las cosas" 53 . Y en efecto, durante el siglo XX, ha habido varios intentos de reforma hasta llegar a la nueva Ley de 1985. La Ley de Aguas de 1866, como ya se expuso, tuvo que adaptar su texto, en primer lugar, a la Ley de 20 de febrero 1870, de Canales y Pantanos de Riego y a su Reglamento de 20 de diciembre de 1870, tras haber colisionado con la Ley de Minas de 28 de diciembre de 1868 en cuanto al dominio de las aguas subterráneas se refiere -como más arriba se expuso- y, posteriormente, con el cambio de régimen político, tendría, también, que acomodarse a la Ley de Bases para la legislación de Obras Públicas de 19 de diciembre de 1876 y a la inmediata a ésta, la Ley General de Obras Públicas de 13 de abril de 1877 y su Reglamento de 6 de julio de 1877, bajo cuyo entorno legislativo nace la Ley de Aguas de 1879 dentro del nuevo marco ideológico del fortalecimiento de la Administración Pública que tan debilitada había quedado, en este ámbito, en el anterior régimen político. De la evolución ${ }^{54}$ histórica es destacable el Proyecto de Sagasta de 21 de

53 Jordana de Pozas en Martín-Retortillo Baquer, S. op. ct. "Sobre la reforma de la Ley de aguas” Revista de la Administración Pública núm. 44-1964; p.29.

54 Martín-Retortillo Baquer, S. op. cit. "Sobre la reforma de la Ley de aguas" Revista de la Administración Pública núm. 44-1964, CEPC; p.p. 25- 57. 
febrero de 1902 que contemplaba las concesiones de aguas públicas y su correspondiente inscripción en el Registro como aprobación legal de las mismas. El Proyecto no llegó a prosperar. En octubre de 1910, el Gobierno, bajo la Presidencia de Canalejas, presenta un nuevo Proyecto de reforma de la Ley de Aguas que se centra en las concesiones de los aprovechamientos de aguas, especialmente aquellos destinados a nuevas tecnologías hidroeléctricas, declarando obligatoria la inscripción del aprovechamiento en el Registro, aprovechamiento que deberá gozar de concesión administrativa. Pero no hay referencia alguna a las aguas subterráneas y su dominio, verdadero caballo de batalla de la confluencia de intereses contrapuestos. Tampoco este Proyecto llegó a ver la luz. Como la legislación recoge la autorización expresa del dueño de un terreno para hacer calicatas en él, los Reales Decretos de 15 de julio de 1905 y 2 de junio de 1910 declaran la posibilidad de "expropiación forzosa de los suelos debajo de los cuales se encontrasen, o existiere la presunción de ello, aguas subterráneas, en la misma forma que para la ejecución de obras públicas". Por otra parte, el Código Civil, aparecido en 1889, no resolvió, como ya se ha expuesto anteriormente, el conflicto inventor-dueño del suelo ya que no hace declaraciones expresas sobre el dominio del subsuelo, como sí había hecho la Ley de Minas de 1868.

De nuevo se quiso, en 1921, reformar la Ley de Aguas de 1879, adaptándola a la realidad circundante, mediante un Anteproyecto suscrito por el entonces Ministro de Fomento, De la Cierva y Peñafiel, del Gobierno presidido por Manuel Allendesalazar. Sus puntos más destacables contemplaban la suspensión de la perpetuidad de las concesiones de agua para aprovechamientos industriales y la revisión de todas las concesiones para instruir los correspondientes expedientes de caducidad, respetándose los derechos adquiridos, pero para el reconocimiento de los mismos, era condición necesaria que se encontraran debidamente inscritos en el Registro de Aprovechamientos. Muy importante era también la derogación del Artículo 149 de la Ley -precepto tratado más arriba- con lo que desaparece el derecho de aprovechamiento por el procedimiento de la prescripción, debiendo derogarse también, a este respecto, el Artículo 409 del Código Civil, estableciéndose, pues, la concesión como el único medio válido para adquirir aprovechamientos especiales de aguas públicas, siendo la Administración la que concursase los aprovechamientos, siempre y cuando se trate de aprovechamientos relacionados con obras realizadas por el Estado. Pero de nuevo, este Anteproyecto queda sin desarrollo posterior. 
Muchos han sido los intentos habidos para reformar la Ley de Aguas que nos ocupa, destacando Martín-Retortillo (1964) toda una batería legislativa de Reales Órdenes; Decretos y Decretos-Leyes, producida a lo largo de los años, a la que califica de "normatividad complementaria que no ha modificado fundamentalmente a la Ley", $\mathrm{y}$, sin embargo, añade que han venido quedando al margen del texto de 1879 "aspectos importantísimos y fundamentales de nuestra ordenación jurídica de las aguas", admitiendo que es comprensible la dificultad de una reforma en este ámbito legislativo por "la trama de intereses que entran en juego, e incluso los que tienen lugar en el seno de la propia Administración". Pero la Ley de Aguas de 1879 fue siempre impregnando conceptualmente de sí misma todos los proyectos surgidos para su propia reforma y así lo expone Gil Olcina ${ }^{55}$ manifestando que "el Avance de un Plan General de Pantanos y Canales de Riego de 1899, el Plan General de Canales de Riego y Pantanos de 1902, con sus aditamentos de 1909, 1916, 1919 y 1922, la actuación de las Confederaciones Sindicales Hidrográficas a partir de 1926, el I Plan Nacional de Obras Hidráulicas (1933) y el Plan General de Obras Hidráulicas, incluido en el Nacional de Obras Públicas de 1940, tienen en común, además de su carácter hidráulico, la impronta regeneracionista y su elaboración en el marco de la Ley de Aguas de 13 de junio de 1879".

Ya, a finales del siglo XX, merced al conocimiento alcanzado por el desarrollo científico hidrogeológico y tecnológico, que revela el carácter único de las aguas en el ciclo hidrológico a la vez que se logran mecanismos técnicos de alta capacidad de extracción de las aguas subterráneas, se llega, finalmente, a la publicación de la Ley 29/1985, de 2 de agosto, de Aguas, que transforma en Públicas las aguas subterráneas, determinándolo así su Artículo Uno.2 que dispone que "las aguas continentales superficiales, así como las subterráneas renovables, integradas todas ellas en el ciclo hidrológico, constituyen un recurso unitario, subordinado al interés general, que forma parte del dominio público estatal como dominio público hidráulico". No obstante, esta Ley, por la que el Código Civil pasa a ser supletorio de la misma, hereda de sus dos antecesoras una vocación de mantenimiento de los derechos adquiridos que junto con la también voluntad de alcanzar los hitos que se propusieron los anteriores intentos de modificación, referentes a la derogación del Artículo 149 de la Ley de Aguas de 1879, con lo que desaparece el derecho de aprovechamiento por el procedimiento de prescripción,

55 Gil Olcina, A. "Del Plan General de 1902 a la planificación hidrológica". Investigaciones Geográficas (España), Nº 25, 2001, págs. 5-32

(C) UNED. Revista de Derecho UNED, núm. 27, 2021 
debiendo derogarse también, a este respecto, el Artículo 409 del Código Civil, establece un régimen transitorio complejo que generó durante años una enorme controversia jurídica con gran conflictividad contenciosa.

\section{CONCLUSIONES:}

La historia de España se enmarca en unos parámetros básicos naturales como son sus diferentes climatología, topografía y geografía, pero fundamentalmente el agua, desigualmente repartida, destaca por su importancia. En el siglo XIX, pese a sus enormes tensiones políticas, se genera un gran interés por el desarrollo socioeconómico que debe pivotarse alrededor de la agricultura y, consecuentemente, del agua para el regadío. Pero las formas de actuación consuetudinarias y una estratificación social basada en la adscripción impedían un mejor progreso social al tiempo que enfrentaba intereses de terratenientes en la distribución del agua para riego encaminados a la transformación de tierras para cultivo, siendo, por tanto, el agua un elemento clave para el logro de incrementos patrimoniales. Fruto de estos intereses fue una profusión legislativa, acumulativa y de aluvión, exenta de sistematización que generaron un corpus complejo y desordenado. Es la Ley de Aguas de 1866 la que enfrenta el desafío de compendiar en una sola Ley toda esa legislación dispersa, proponiéndose establecer reglas que definieran las aguas pertenecientes al dominio público y al dominio privado.

Tras su promulgación, la alternativa política motivada por la revolución de 1868 genera importantes cambios legislativos por lo que esta Ley de Aguas, sin desarrollo reglamentario aún, tuvo que sufrir adaptaciones a nuevas normativas, siendo sustituida, en el marco político de la Restauración, por la Ley de Aguas de 1879 que continuó su misma trayectoria conceptual, pero centrando su normativa en las aguas terrestres, trasladándose la parte de aguas marítimas a la Ley de Puertos de 7 de mayo de 1880. La Ley, que introduce el principio de utilidad pública como motivo de expropiación forzosa, con la indemnización que correspondiera, y regula los derechos y deberes que se derivan del dominio de las aguas, de su uso y de su aprovechamiento, sigue manteniendo un régimen jurídico privatista para las aguas subterráneas y otro administrativista para las aguas superficiales públicas y, al igual que la Ley de Aguas de 1866, admite la posibilidad de la prescripción como título legítimo para llevar a cabo el aprovechamiento de aguas públicas. No obstante, diez años después, el Código Civil de 1889, regula las Aguas, 
en sus Artículos 407 a 425, por lo que se produce la existencia de dos normativas sobre la misma materia. Sus diferentes enfoques en algunos puntos generaron problemas en su aplicación al ser considerada esta última norma más privatista que la Ley de Aguas que queda supletoria del Código Civil.

Para esta Ley de 1879 tampoco hubo desarrollo reglamentario, si bien algunas Reales Órdenes posteriores aclaraban puntos confusos, a pesar de lo cual ha tenido una duración de ciento seis años y aunque a lo largo de ellos ha habido intentos de sustituirla no llegó ninguno de ellos a prosperar, siendo finalmente derogada por la Ley de Aguas, de 2 de agosto de 1985, que también derogará los Artículo 407 al 427 del Código Civil, y cuya normativa, avanzando en una línea de demanialización, hace públicas las aguas subterráneas, pero, deseando respetar los derechos adquiridos bajo la anterior legislación, establece un régimen jurídico transitorio cuya aplicación provocó una importante conflictividad contenciosa, siendo "una de las causas de la actual falta de control administrativo de las fuentes subterráneas" 56 .

\section{BIBLIOGRAFÍA.}

ABellán Contreras, FJ. El aprovechamiento de las aguas en la Ley 13 de junio de 1879. Trayectoria de un texto legislativo a la luz de la optimización y eficacia de los recursos hídricos. Universidad de Alicante, 2014. Congresos Universidad Politécnica de Valencia, 2015. http://dx.doi.org/10.4995/ISL2014.2014.148.

Alonso Moya, F. Sobre las aguas de dominio público y de dominio privado. Revista de la Administración Pública, núm. 4; 1951. ISSN 0034-7639. Ed.: CEPC.

Álvarez Fernández, M. El abastecimiento de agua en España. Ed.: Civitas, 2004. ISBN: 84-470-2146-7.

Calvo Pereyra, M. De las aguas tratadas bajo el punto de vista legal y con aplicación a las construcciones y abastecimiento de las ciudades en sus diferentes usos. Ed.: Eusebio Aguado; 1862. Universidad Complutense- 5320573704. Departamento de Derecho Administrativo.

${ }^{56}$ Fanlo Loras, A. "La gestión del agua en España: experiencias pasadas, retos futuros". Universidad de la Rioja, 2001, p.45, en Tamames R. y Aurín R. "Gobernanza y Gestión del Agua: modelos público y privado", 2015, p.57.

(C) UNED. Revista de Derecho UNED, núm. 27, 2021 
Del SAZ, S.: “Cuál es el contenido de los derechos privados sobre las aguas subterráneas" y Moreu Ballonga, J.L. "Los problemas de la legislación sobre aguas subterráneas en España: Posibles soluciones". Papeles del Proyecto de Aguas Subterráneas (PAS). Ed.: Fundación Marcelino Botín, 2001. ISBN: 84-95516-35-7.

El Consultor de los Ayuntamientos. Legislación De Minas. Ed.: ImPRENTA ENRIQUE DE LA RIVA; MADRID, diciembre 1875. Biblioteca de la Facultad de Derecho de Sevilla. http:/fama2.us.es/fde/ocr/2006/ legislacionDeMinas.pdf

FraX Rosales, E. Las leyes de bases de obras públicas en el siglo XIX. Revista de Estudios Políticos (Nueva Época). ISSN 0048-7694, núm. 93 (julio-septiembre 1996).

Fundación Marcelino Botín. "Papeles del Proyecto de Agua SubteRRÁNEA”. ISBN: 84- 95516-35-7.

Gallego Anabitarte, A; Menéndez Rexach, A; Díaz Lema, J.M. El Derecho de aguas en España". Centro de Publicaciones del Ministerio de Obras Públicas y Urbanismo. Madrid, 1986. ISBN: 84-7433-408-X.

Gay de Montellá, R. y Massó Escofet, C. Tratado de la legislación de aguas públicas y privadas, comentarios a los preceptos de la ley de Aguas, a la legislación complementaria y a la jurisprudencia. Tomo I: Legislación Fundamental. Ed.: Casa Editorial Bosch; Barcelona 1956. $2^{\text {a }}$ Edición.

Gay de Montellá, R. y Massó Escofet, C. Tratado de la legislación de aguas privadas. Tomos I: Legislación Fundamental y Tomo II Legislación Complementaria. Ed.: Casa editorial Bosch; Barcelona, 1956. $3^{\text {a }}$ Edición.

GIL Olcina, A.; Morales Gil, A. Hitos históricos de los regadíos españoles. Ed.: Ministerio de Agricultura, Alimentación y Medio Ambiente; SGT, 1992. ISBN: 84-7479- 915-5.

Guaita Martorell, A.: "Derecho Administrativo. Aguas, Montes, Minas”. Ed. Civitas. 1982; Madrid. ISBN: 9787473982092.

Jordana De Pozas, L. La evolución del Derecho de Aguas en España y en otros países. Revista de la Administración Pública, número 37; Estudio,1962; ISSN-0034- 7639. Ed.: CEPC.

Martín-Retrortillo Baquer, S. La elaboración de la Ley de Aguas de 1866. Estudio, 1960. Revista de la Administración Pública, núm. 32. ISSN-0034-7639. Ed.: CEPC. 
Martín-Retortillo Baquer, S. Sobre la Reforma de la Ley de Aguas. Estudio, 1964. Revista de la Administración Pública, núm. 44; ISSN-0034-7639. Ed.: CEPC.

Martín Retortillo Baquer, S. La Ley de Aguas de 1866, antecedentes y elaboración. Ed.: Centro de Estudios Hidrológicos, 1963. ISNI: 81484852.

Martín-Retortillo Baquer, S. Dictamen sobre la perpetuidad de las concesiones de canales para riego otorgadas a empresa interpuesta con anterioridad a la ley de aguas de 1866. Estudio, 1964. Revista de administración Pública núm. 45; ISSN- 0034-7639. Ed.: CEPC.

Martín Retortillo Baquer, S. El Derecho de aguas. Ed.: Civitas; Madrid 1997. ISBN: 84- 470-0875-4.

Moreu Ballonga, J.L. “Ocupación, hallazgo y tesoro” Ed. Bosch 1980, Barcelona. ISBN: 9788471628107.

Moreu Ballonga, J.L. Ponencia "la difícil distinción entre aguas públicas y privadas y sus consecuencias". Jornada de "Sostenibilidad en los usos agrícolas del agua". Junio-2017. https://www.youtube. $\mathrm{com} /$ watch?v=0F_dMRK-upI

Nieto García, A. Aguas subterráneas: subsuelo árido y subsuelo hídrico". Revista de la Administración Pública, núm. 56. (mayoagosto,1968). ISSN 0034-7639. Ed.: CEPC. También en edición del Cabildo Insular de Tenerife-Aula de Cultura, 1968.

NúÑEz de PRAdo y Fernández, J. Consideraciones sobre el Decreto Ley de 14 de noviembre de 1868. Revista de Obras Públicas, XXII; Tomo I, Año I. Madrid, 1874. ISSN-0034-8619. Colegio Ingenieros de Caminos, Canales y Puertos.

Palau y Catalá, M. Ley de Aguas de 13 de junio de 1879. Comentarios, referencias y notas críticas. Ed.: Librería de las SS Teixidó i Parera. Barcelona, 1879; y Librería de D. Antonio Sanmartín; Madrid.

Pérez Pérez, E. Disposiciones decimonónicas sobre aguas. Ley de 1879. https://www.mapa.gob.es/ministerio/pags/Biblioteca/fondo/ pdf/9999_7.pdf

PÉREz PÉREz, E. Estudios jurídicos sobre la propiedad, aprovechamientos y gestión del agua. MOPT; Madrid, 1993. ISBN: 84-7433-899-9.

Pérez PÉREz, E. Legislación y Administración del Agua en España (criterios para su reforma). Editora Regional de Murcia, 1981. ISBN: 84-500-4677-7. 
Tamames, R. y Aurín R. Gobernanza y Gestión del Agua. Modelos Público y Privado". Ed.: Profit, 2015. ISBN: 97 8-84-16583-00-3.

Valle Ribas, J. Ley de Aguas de Aguas de 1866 https:/gutierrezlabrador.com/la-ley-de- aguas-de-1866/ ; 2019.

\section{NORMATIVA REFERENCIADA.}

\section{A.- FUENTES INDIRECTAS.}

De Pérez Pérez E. "Disposiciones decimonónicas sobre aguas".

R.D. DE 19 DE MAYO DE 1816; R.D. DE 31 DE AGOSTO DE 1819; PP. 184188

De Mínguez Ben, E. "Antecedentes y elaboración de la primera Ley de Expropiación".

HTTPS:/DIALNET.UNIRIOJA.ES/DESCARGA/ARTICULO/893208.PDF

LEY DE EXPROPIACIÓN FORZOSA DE 1836. P.9

REAL INSTRUCCIÓN PARA PROMOVER Y EJECUTAR LAS OBRAS PÚBLICAS APROBADA POR R.D. DE 10 DE OCTUBRE DE 1845.

De Pérez Pérez E. "Disposiciones DECIMONÓNICAS SOBRE AGUAS".

R. ORden de 14 de MARZo de1846; R. ORdEN dE 21 dE AGOSTO dE 1849; PP.186-188

LEY DE 24 DE JUNIO DE 1849 SOBRE SERVIDUMBRE DE ACUEDUCTO. PP.189.

De Valle Ribas, J. "Ley de Aguas de 1866". https://gutierrezlabrador. com/la-ley-de- aguas-de-1866/ ; 2019. R.D. 11 de julio de 1856.

De Pérez Pérez E. "Disposiciones deCIMONÓNICAS SOBRE AGUAS".

R. ORDEN DE 5 DE ABRIL DE 1859. PP. 190: R.D. DE 27 DE ABRIL DE 1859; P.P.187

De Calvo Pereira M. “De las aguas tratadas bajo el punto de Vista LEGAL Y CON APLICACIÓN A LAS CONSTRUCCIONES Y ABASTECIMIENTOS DE LAS CIUDADES EN SUS DIFERENTES USOS", p.313: R.D. de 29 de abril de 1860.

\section{B.- FUENTES DIRECTAS.}

Proyecto de Código Civil de 1851. "De las Leyes y sus efectos y de las reglas generales para su aplicación". 
Ley de Aguas de 3 de agosto de 1866.

Ley de Minas, de 4 de marzo de 1868.

Reglamento de desarrollo de la Ley de Minas de 24 de junio de 1868.

Bases Generales para la nueva legislación de Minas, aprobada por Decreto Ley de 29 de diciembre de 1868, modificado su Art. 19 y varias Reales Órdenes aclaratorias por la Ley de 24 de julio de 1871.

Decreto Ley de 14 de noviembre de 1868 que establece Bases Generales para nueva legislación de Obras Públicas.

Ley "sobre Canales y Pantanos de riego", de 20 de febrero de 1870.

Decreto de 20 de diciembre de 1870 por el que se aprueba el Reglamento para la aplicación de la Ley de 20 de febrero de 1870 "sobre Canales y Pantanos de Riego".

Real Orden de 5 de diciembre de 1876 estableciendo que el Decreto Ley de noviembre de 1968 no puede afectar a la propiedad adquirida bajo la anterior legislación.

Real Orden de 30 de marzo de 1877, aclaratoria de la anterior de 5 de diciembre.

Ley General de Obras Públicas de 13 de abril de 1877, recogiendo las Bases aprobadas por las Cortes en la Ley de 19 de diciembre de 1876.

Reglamento, de 6 de julio de 1877, que desarrolla la Ley General de Obras Públicas.

Ley de Aguas de 13 de junio de 1879.

Ley de Puertos de 7 de mayo de 1880.

Real Orden de 5 de junio de 1883, sobre alumbramiento de aguas subterráneas en terrenos de dominio público.

Real Orden de 2 de mayo de 1891, aportando disposiciones aclaratorias a la Ley de Aguas de 1879.

Ley de Bases de 11 de mayo de 1888 por la que se autoriza al Gobierno para publicar un Código Civil con arreglo a las condiciones y bases de esta Ley.

Real Decreto de 24 de julio de 1889 por el que se publica el Código Civil. 


\section{C.- JURISPRUDENCIA.}

STC 227/1998, de 29 de noviembre, sobre Recurso de inconstitucionalidad 